\title{
Targeted Imaging for Cell Death in Cardiovascular Disorders
}

Aditya Shekhar, ${ }^{\mathrm{a}}$ Peter Heeger, MD, ${ }^{\mathrm{a}}$ Chris Reutelingsperger, $\mathrm{PHD},{ }^{\mathrm{b}}$ Eloisa Arbustini, MD, $\mathrm{PHD},{ }^{\mathrm{c}}$ Navneet Narula, MD, Leonard Hofstra, MD, $\mathrm{PHD}_{\mathrm{H}}{ }^{\mathrm{e}}$ Jeroen J. Bax, MD, $\mathrm{PHD}^{\mathrm{f}}{ }^{\mathrm{f}}$ Jagat Narula, MD, $\mathrm{PHD}^{\mathrm{a}}$

\section{ABSTRACT}

Cell death is desirable in cancer cells and undesirable in organs with limited regenerative potential, like the heart. Cell death comes in many forms, but only apoptosis and to a lesser degree necrosis is currently relevant to the clinical imager. Noninvasive imaging of cell death is an attractive option to understand pathophysiology, track disease activity, and evaluate response to intervention. Apoptosis seems to be the most promising target for imaging cell death, because it could be reversible and might be modulated with interventions. Molecular, nuclear, optical, or magnetic resonance imaging-based methods have been developed to identify intermediate steps in the apoptosis cascade. Animal studies show promising results for noninvasive imaging in various cardiovascular diseases. Human studies have shown feasibility, but clinical use is yet inconclusive. Newer technologies offer promise, especially for tracking apoptosis in evaluation of novel therapeutic interventions. (J Am Coll Cardiol Img 2018;11:476-93) @ 2018 Published by Elsevier on behalf of the American College of Cardiology Foundation.

ell death is an important feature of both life and death (1). It is intricately controlled in embryonic development as well as in postnatal life, when pathways are turned on and off as needed in exquisitely choreographed patterns, as best seen in apoptotic cell death. The machinery for controlled cell death, especially via apoptosis, persists into adult life to get rid of unwanted cells including cancerous and senescent ones, controlling the immune response as well as providing immune privilege in organs where cell death-mediated inflammation can be harmful. However, these same tightly regulated pathways can get activated in many diseases and once out of the carefully controlled environment, can have fateful consequences. Cell death is undesirable in heart diseases, which has limited regenerative capacity but may be desired for cancer cell death in neoplasia. In addition, there is strong evidence that cell death, especially of the apoptotic variety, can be modulated. In either case, detection, monitoring of cell death, and assessment of therapeutic response might need accurate measurement of apoptosis $(2,3)$. Visualizing cell death, especially through noninvasive imaging, is thus critical for understanding disease, tracking its course, prognostication, and even directing targeted therapy as well as measuring the success of such treatments.

\section{HOW SHOULD AN IMAGER THINK ABOUT CELL DEATH?}

At least 12 forms of cell death have been described so far (4), and more are being reported; however, only

From the ${ }^{a}$ Icahn School of Medicine at Mount Sinai, New York, New York; ${ }^{b}$ Maastricht University Medical Center, Maastricht, the Netherlands; ' Centre for Inherited Cardiovascular Diseases, IRCCS Foundation University Hospital Policlinico San Matteo, Pavia, Italy; ${ }^{\mathrm{d}}$ New York University Langone Medical Center, New York, New York; ${ }^{\text {} V r i j e ~ U n i v e r s i t y ~ M e d i c a l ~ C e n t e r, ~ A m s t e r d a m, ~ t h e ~}$ Netherlands; and the ${ }^{\mathrm{f}}$ Leiden University Medical Center, Leiden, the Netherlands. Dr. Reutelingsperger has served as a scientific advisor to Annexin Pharmaceuticals and Matisse Pharmaceuticals. Dr. Bax's institution, The Department of Cardiology at Leiden University Medical Center, has received unrestricted research grants from Biotronik, Medtronic, Boston Scientific, and Edwards Lifesciences. All other authors have reported that they have no relationships relevant to the contents of this paper to disclose. 
apoptosis, and to a lesser degree necrosis and autophagy, could be seen as a current priority for the imager (Central Illustration). All forms of cell death follow a rather similar general pattern of onset and progression-death programs are activated by a variety of factors including ischemia, cytokines, oxidative stress, starvation, toxins, and infections. These triggers either act at the cell surface, activating deathassociated receptors (extrinsic pathways), or, as in radiation injury, act intracellularly (intrinsic pathways); often, both pathways are activated in an interrelated manner to various degrees. Most pathways converge to the mitochondria (5), and often it is the degree of mitochondrial disruption that decides how the cell dies.

Necrosis (Central Illustration), the most wellestablished form of cell death, signifies irreversible damage to the mitochondria-opening of the mitochondrial permeability transition pore results in collapse of its voltage gradient and thus energy depletion (6). It is often acute and dramatic, provoking strong inflammatory and immune responses in its neighborhood through en mass release of cellular contents. It is imaged to detect and quantitate damage rather than with any hope of reversing it. Apoptosis and autophagy are more nuanced, in that death occurs in a controlled manner without provoking an inflammatory response. Apoptosis (Central Illustration) is a form of programmable cell death, where a very specific death pathway made up of sequential steps is activated to remove cells. Autophagy is a form of lysosomal degradation of cell contents within the degenerate or senescent cell itself, but there is controversy whether it is more of a survival mechanism rather than committed cell death. These forms of cell death show an insidious cellular involution or digestion without macroscopically disrupting the cell membrane, and remnants are engulfed by scavenger cells like macrophages; thus, dying cell bodies disappear without much trace, which makes imaging them more difficult. However, they can contribute to severe organ dysfunction, especially when they occur in sufficient magnitude and over a significant time period in organs with poor regenerative capacity like the heart. More importantly, because apoptosis (and to a lesser extent autophagy) can be modulated, imaging it might have important implications for therapy and preserving organ structure and function. Yet another type of cell death, necroptosis (7), is gaining significant interest (Central Illustration, lower left panel); it is a condition where the cellular morphology is consistent with necrosis, but its execution appears to be programmed like in apoptosis (7). Necroptosis-triggering stimuli create a necrosome that induces membranous leak, and similar to cellular necrosis, one might be able to use intracellular targets for noninvasive imaging.

It appears that many of these pathways share elements and can influence each other $(8,9)$. Damaged mitochondria are potent triggers of apoptosis, and removing them via autophagy can attenuate apoptosis. Similarly, apoptosis and necroptosis share a seesaw relationship, where caspases mediate apoptosis, but inefficient caspase 8 activation shifts the pathway to death via necroptosis. In each of these processes, depending on the energetic state, the cell may complete apoptosis if adenosine triphosphate (ATP) levels are adequate for preserving pumps, may enter a zombie state (where the cell survives by turning down most energy-intensive processes, like contraction, and concentrates on barely staying alive) if ATP is marginal, and ends in necrosis if ATP levels are depleted so much that they cannot sustain the membrane pumps. The Central Illustration shows various targets that are amenable to imaging in each of the major forms of cell death.

\section{MOLECULAR IMAGING TECHNIQUES, AGENTS, AND TARGETS FOR IMAGING NECROTIC CELLS}

Interest in imaging necrosis peaked 2 decades ago, and innovation has now shifted toward apoptosis imaging; necrotic imaging will thus be considered only briefly in this review. The waning interest in molecular imaging of necrosis is understandable, because unlike apoptosis, it is a late stage of cell injury that limits options for intervention. Moreover, necrosis is, under many circumstances, rather an extension of apoptotic injury, and interference in the apoptotic process could restrict necrotic cell loss (9).

A critical difference between imaging apoptosis and necrosis is that the latter allows for targeting intracellular constituents secondary to disrupted cell membranes that are no longer a barrier to penetration of imaging agents. However, this condition also creates difficulties in imaging, because many intracellular targets could wash out (e.g., histones) or offer shorter time windows for imaging, and might need at least some residual perfusion to carry the tracer to the desirable target. Finally, imaging should be able to differentiate acute from subacute necrosis and necrosis from apoptosis when both coexist, as they frequently do.

Two different strategies have been used to detect cell necrosis. Static imaging techniques detect

A B B R E V I A T I O N S
A N D A C R O N Y M S
GSAO = 4-(N-[S-
glutathionylacetyl]amino)
phenylarsonous acid
PE =
phosphatidylethanolamine
PET = positron emission
tomography
PS = phosphatidylserine
SPECT = single-photon
emission computed
tomography




\section{CENTRAL ILLUSTRATION Pathways of Apoptotic, Necroptotic, and Necrotic Cell Death}
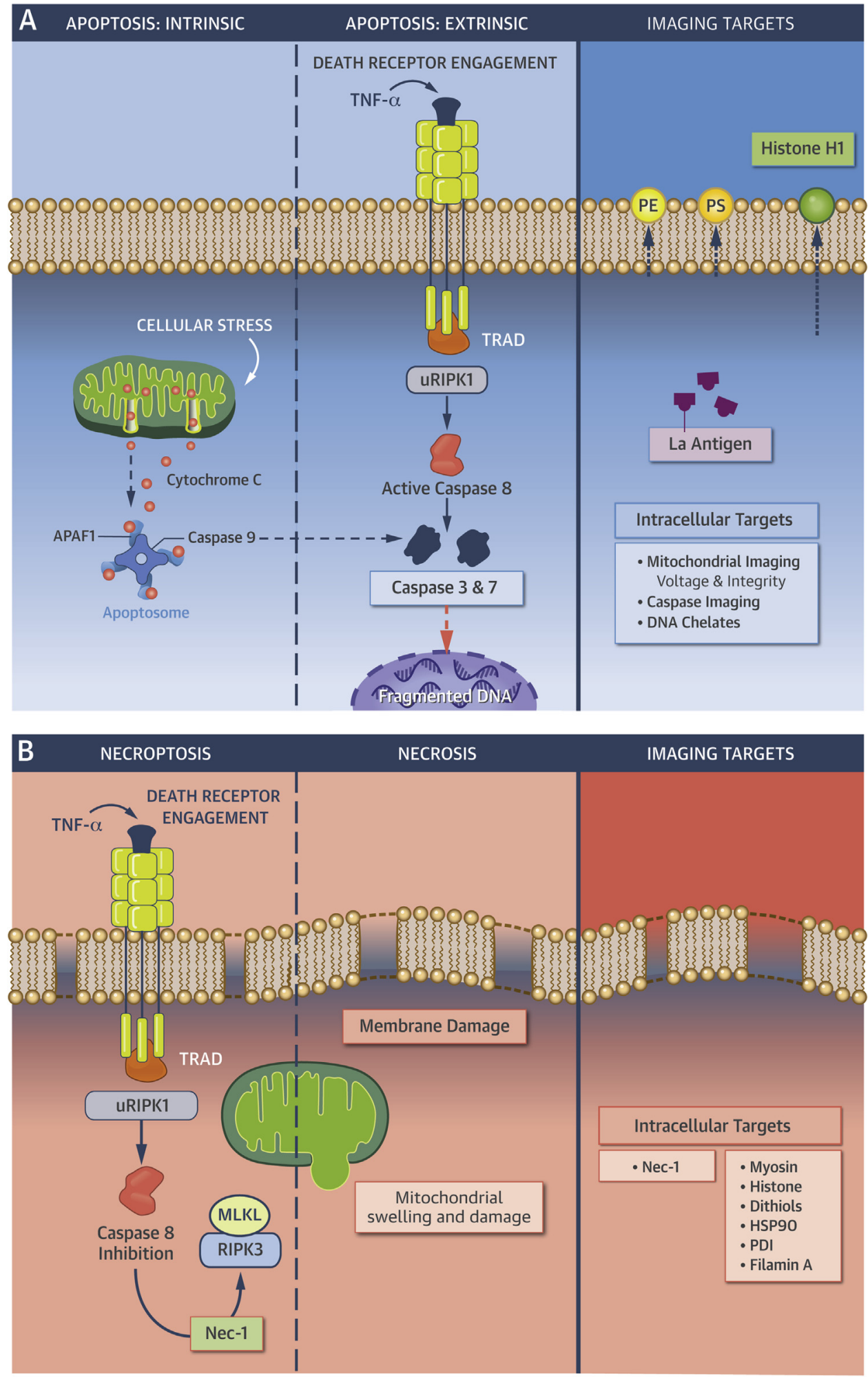

Shekhar, A. et al. J Am Coll Cardiol Img. 2018;11(3):476-93. 
morphological changes (structure, function, and chemistry) and thus image the effect of damage due to cell death. Other techniques allow real-time imaging of cell death itself, using radionuclide tracers that penetrate and target intracellular markers to localize cells undergoing necrosis. The former includes echocardiography, cardiac magnetic resonance (CMR), and computed tomography (CT). CMR can detect acute myocardial infarction (MI), often within 20 to 30 min of onset through detection of edema and subsequently through detection of replacement fibrosis by late gadolinium enhancement (LGE). $\mathrm{T}_{2}$ mapping can detect edema but is not specific for the necrotic tissue and cannot differentiate acute from subacute myocardial injury. In addition, these detect residual effects of myocardial necrosis rather than the process, and hence, are least useful in finding an indication for acute therapeutic intervention targeted to modulate cell death.

The other strategy is to bind intracellular contents exposed by necrotic cell membranes. Early studies of vital fluorochromes such as propidium iodide exploited this access to intracellular contents, and other agents, such as indium-111-labeled antimyosin antibodies (10), technetium-99m $\left({ }^{99 \mathrm{~m}} \mathrm{Tc}\right)$-pyrophosphate (11), and ${ }^{99 m}$ Tc-labeled D-glucaric acid (12), later refined this further. Antimyosin antibody imaging has the most data and has been used to detect necrosis in a number of pathologies including MI, myocarditis, cardiomyopathy, and transplant rejection (13). More recently, 4-(N-[S-glutathionylacetyl]amino) phenylarsonous acid (GSAO), an arsenic compound tagged with indium-111 (Figure 1) has been used to home into dithiol-containing substrates in the cell to identify cell death (14). It has an absolute requirement for membrane disruption and has little persistence in the extracellular space, which makes for better images.

Magnetic resonance (MR) imaging allows for sophisticated imaging of cell death, such as, with gadoporphyrin (which accumulates in necrotic tissue), using magnetic nanoparticles coupled to an antibody (iron oxide-labeled antimyosin antibodies) or gadolinium with diethylenetriaminepentacetate + annexin-V-cross-linked iron oxide can harness the advantages of MR to image cellular necrosis, track the time course of changes, and distinguish necrosis from apoptosis when they occur together (15). Deoxyribonucleic acid (DNA)-binding chelates are a marker for necrosis (16), and newer DNA-binding gadolinium chelates (such as Gd-TO) have been developed (17) that specifically bind to exposed DNA in acutely necrotic cells, but do not wash away like standard gadolinium and allow for studying the time course of acute necrosis (Figure 2). As small molecules, they might avoid issues like renal and hepatic retention that are seen with large molecules, like antibodies. Further, hyperpolarized ${ }^{13} \mathrm{C}$-carbon $\mathrm{MR}$ imaging, where polarization of the magnetic spins is used to increase magnetization and thus, the signal, many fold during spectroscopy or MR-based imaging, is being used to detect and localize in necrotic tissues. It

\section{CENTRAL ILLUSTRATION Continued}

(A) APOPTOSIS. There are 2 basic pathways to mediate apoptosis-the intrinsic pathway or the extrinsic pathway. (Left) The intrinsic pathway, where intracellular triggers like cellular stress lead to mitochondrial permeability transition pore formation, collapsing voltage, leak of cytochrome C, and formation of the apoptosome (a combination of APAF1, Caspase 9, and cytochrome C). This can activate the executioner caspases ( 3 and 7), resulting in deoxyribonucleic acid (DNA) fragmentation and the classic apoptotic morphology. (Middle) The extrinsic pathway for apoptosis. Engagement of the death receptors (with TNF alpha, FAS, or other ligands) results in TRAD-RIPK1 activation if RIPK1 is disubiquitylated (URIPK1), and mediates apoptosis via caspase 8 and then by activating the executioner caspases 3 and 7 . This again results in DNA fragmentation and apoptosis. In every process of apoptosis, depending on the energetic state, the cell may complete apoptosis if ATP levels are adequate for preserving pumps, enter a zombie state if ATP is marginal, and end in necrosis if ATP levels are depleted so much that that they cannot sustain the membrane pumps. (Right) Possible imaging targets for apoptosis can be exposed to the cell surface or intracellular. The former include exteriorized cell surface phospholipids like phosphatidylethanolamine (PE) and phosphatidylserine (PS), exteriorized histones, and the La antigen that translocates from the nucleus to the cytoplasm (which can be accessed for imaging in later stages of apoptosis). Nonexteriorized targets include probes for mitochondrial voltage and its integrity, and caspase activation. Some gadolinium-based CMR probes can access DNA fragments in later stages of apoptosis. (B) Necroptosis and necrosis. (Left) The necroptosis pathway uses the same pathways as apoptosis but with some differences-should TRAD-RIPK1 activation occur when RIPK1 is disubiquitylated (URIPK1) and there is caspase 8 inhibition, the cell gets diverted from an apoptotic fate and enters the necroptosis pathway instead. This is mediated via the RIPK3-MLKL complex and results in a necrotic morphology (membrane permeabilization and swelling of mitochondria with ATP depletion). Imaging targets for necroptosis include Nec-l-based probes and finding morphological changes in the membrane and mitochondria that resemble a mixture of apoptosis and necrosis. However, NEC-1 imaging is in a very early stage of development. (Right) Should the damage be severe or should apoptosis or necroptosis present with severe energy depletion, the process morphs into necrosis, a largely irreversible form of cell death. Because necrosis is associated with significantly compromised membranes, imaging targets for necrosis include many of the intracellular components-myosin, dithiols like HSP9O, Filamin A, and so on. They can be imaged with a number of nuclear and CMR techniques. 
FIGURE 1 Finding Newer Targets for Imaging Cell Death

A

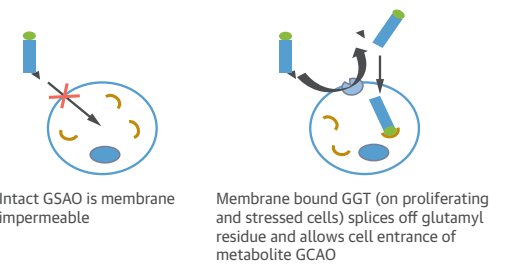
metabolite GCAO Membrane disruption in necrotic cells allows cell entrance of fluorescently or radiolabeled GSA Binding of fluorescent or radioactive
reporter molecules to GSAO prevents binding to GGT and thereby prevents residue and allows cell entrance of
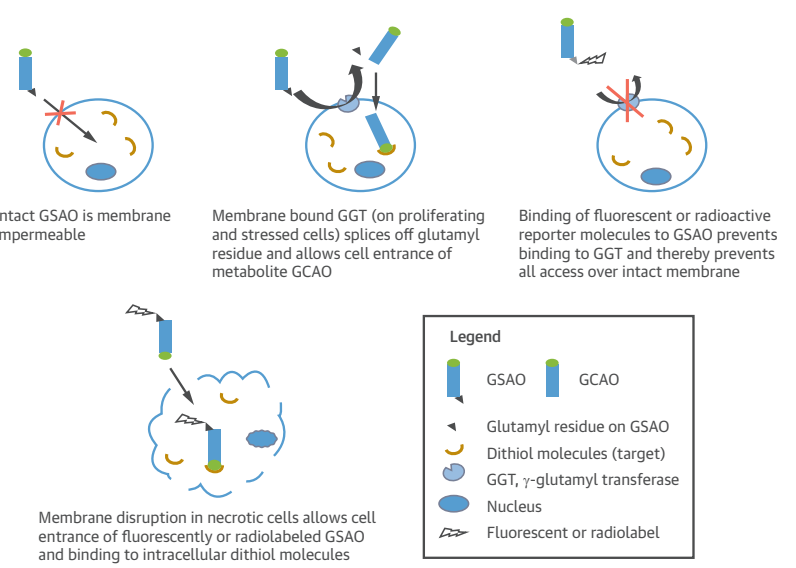

B
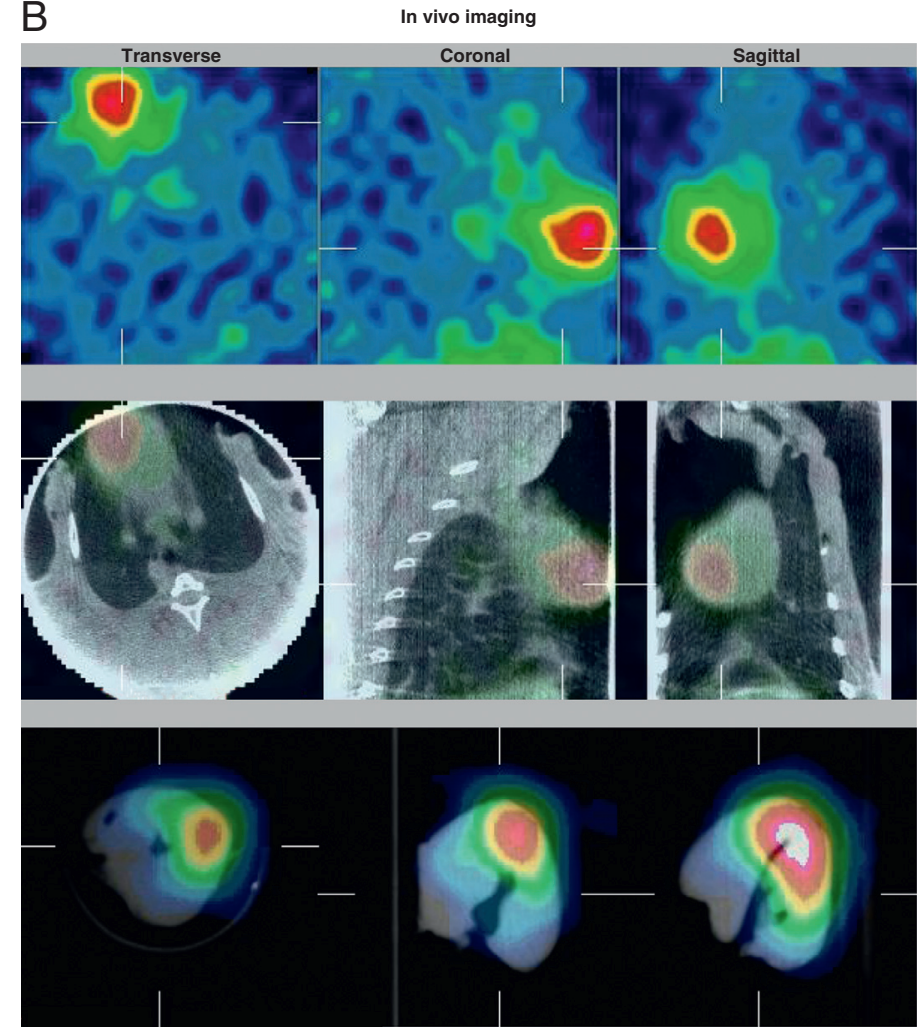

Ex vivo imaging

As also presented in Figure 2, whereas duramycin is being developed as the new agent for apoptosis imaging, 4-(N-[S-glutathionylacetyl]amino)phenylarsonous acid (GSAO) has been reported as a new necrosis targeting agent. (A) Targeting mechanism of GSAO. GSAO binds to dithiol molecules, which are abundant in the intracellular space and virtually absent in the extracellular space. When labelled with radioactive or fluorescent reporter molecules, GSAO cannot negotiate across the cell membrane of healthy cells (top) but gains free access through disrupted membranes of dying cells (bottom). Thus, GSAO accumulates in dying cells. (B) In-111 GSAO imaging in rabbit ischemia-reperfusion model with acute myocardial infarction. In vivo $\mu$ SPECT (top), and fused $\mu$ SPECT/ $\mu \mathrm{CT}$ images can study the biochemistry of necrosis in real time in the living organ $(18,19)$, detecting accumulation of lactate (with reduced bicarbonate production suggesting interruption of the Krebs cycle) or detecting fumarase leakage with resulting malate production to detect and localize in necrotic tissues during ischemia-reperfusion (20). This method can detect early damage compared with the information obtained through scar imaging with CMR-LGE. Molecular imaging is thus providing some exciting avenues to image and protect against cell death $(21,22)$.

Necroptosis has been noted in ischemiareperfusion injury in multiple organs including the heart, kidney, and brain. It is important in sepsis (23), and has a particularly significant role in cancer, where cells try to evade apoptosis (24). Necroptosis imaging is still in its infancy, and most of the detection is in vitro. A small molecule necrostatin-1 (Nec-1) is a specific inhibitor of the main component of the necrosome (RIP1-RIP3 interaction) and has been tagged with a radionuclear tag for imaging necroptosis; necroptosis is prominent in human carotid plaque necrotic core and is thought to be important for plaque vulnerability. Ex vivo imaging shows ${ }^{123}$ I-Nec-1 localizes to the atherosclerotic plaques with necroptotic cells in (human) high-risk atherosclerotic plaques. Mice studies show the power of Nec-1 imaging, because inhibiting necroptosis reduced atherosclerotic lesion size and other indicators of plaque instability (25). No in vivo human studies imaging necroptosis have been undertaken yet.

\section{MOLECULAR IMAGING TECHNIQUES, AGENTS, AND TARGETS FOR IMAGING AUTOPHAGY}

Autophagy imaging is evolving but has remained far behind apoptosis imaging-most of the studies are limited to studying autophagy flux or markers in tissues or in biopsy samples. One reason is that, despite being seen in myocardial ischemia, ischemia/reperfusion (IR) injury, and heart failure, its role is less understood, and it is unclear whether increased

\section{FIGURE 1 Continued}

(middle) revealed intense tracer uptake. There was only minimal uptake of radiotracer control compound In-111 GSCA (not shown). Ex vivo planar images confirmed intense In-111 GSAO uptake (bottom). $\gamma$-counting of myocardial sections confirmed that In-111 GSAO uptake in infarct was higher than in the remote area and higher than In-111 GSCA uptake in the infarct (not shown). Panel A adapted from Tahara et al. (14). 
autophagy mediates heart failure or if it is a peripheral phenomenon (26). A second more important reason is a lack of robust probes coupled to currently available tomographic imaging (27). A cathepsinactivatable near-infrared fluorochrome (CAF-680) has been successfully used for studying the role of modulating autophagy in mice IR injury and tracks change in infarct size reasonably well (28). However, fluorescence molecular tomography use has limited potential for clinical translation. No good studies exist to show autophagy imaging in human health and disease. Future development of traditional imaging probes (e.g., positron-emission tomography [PET]-based) rather than the current fluorescencebased ones will be needed for human translation.

\section{MOLECULAR IMAGING TECHNIQUES, AGENTS, AND TARGETS FOR IMAGING APOPTOTIC CELLS}

Noninvasive imaging of cell death has been mostly directed at apoptosis, given that such cells may still be salvageable, compared with the irreversible damage that necrosis often represents. Apoptosis imaging has been used to understand pathophysiology, direct therapy, and quantitate benefit of therapy, more so in published cancer data than in cardiovascular conditions. A number of targets have been investigated for noninvasive imaging of apoptotic cell death (Central Illustration). These include cell surface markers, detection of membrane permeability, activation of intracellular apoptotic machinery (e.g., caspases), and mitochondrial imaging.

SURFACE MARKERS-EXTERIORIZED PHOSPHOLIPIDS. Nuclear techniques for apoptosis imaging. Phospholipids, such as phosphatidylethanolamine (PE) and phosphatidylserine (PS), which are normally residents of the interior layer of the sarcolemma, are exposed during apoptosis and comprise attractive targets for noninvasive imaging. $\mathrm{PS}$ and $\mathrm{PE}$ accumulate in a time- and damage-dependent manner and result in a concentration that constitutes an attractive target for positively-charged probes, carrying either a diagnostic tracer or even a therapeutic tag. A number of molecules have been deployed for detecting PS exteriorization; the best known among them is annexin- $\mathrm{V}$ complexed to a radionuclide technetium$99 \mathrm{~m}$. It has been even used in early-stage clinical studies (Figures 3 to 5 ).

Annexin-V, a positively-charged, naturally occurring protease with anticoagulant activity, has nanomolar affinity to the negatively-charged PS on the cell surface of apoptotic cells. Radiolabeling a recombinantly produced annexin- $\mathrm{V}$ with ${ }^{99 \mathrm{~m}} \mathrm{Tc}$ generates an attractive probe to image apoptotic cells in numerous cardiovascular disorders (29), including atherosclerosis, MI, heart failure, and transplant rejection, as also in various cancers before and after therapy (30). It has also been safely tested in humans with reasonable results $(2,3,31)$. An iodinated probe, ${ }^{123} \mathrm{I}$-annexin- $\mathrm{V}$, with a bit longer half-life is also being tested, but data on cardiac apoptosis is lacking. Because usual linker technology can target any of the 21 lysine NH2s, other site-specific modifications of annexin- $\mathrm{V}$, including ${ }^{99 \mathrm{~m}} \mathrm{Tc}(\mathrm{CO}) 3$-HIS-cys-annexin- $\mathrm{V}$, ${ }^{99 \mathrm{~m}} \mathrm{Tc}$-annexin-V-117, ${ }^{99 \mathrm{~m}} \mathrm{Tc}-\mathrm{His} 10-a n n e x i n-\mathrm{V}$, or ${ }^{99 m}$ Tc-Cys-annexin- $\mathrm{V}$, or using ${ }^{18} \mathrm{~F}$-labeled annexin- $\mathrm{V}$ might improve efficacy for imaging cell death. It has also been postulated that PS imaging with annexin-V can be used to detect ischemic memory after a brief period of ischemia (32). Of note, annexin- $\mathrm{V}$ is not specific for cardiomyocytes and is taken up by any apoptotic cells, such as macrophages in atherosclerotic necrotic cores $(33,34)$.

Annexin-V's adoption into clinical practice has been slow due to some inherent disadvantages. As a large molecule, it is cleared slowly and results in significant off-target radiation, especially to the kidney (35). Most of the studies involving detection of cell-surface PS have involved ${ }^{99 \mathrm{~m}} \mathrm{Tc}-$ Annexin- $\mathrm{V}$ for single-photon emission computed tomography (SPECT) or SPECT/CT imaging $(36,37)$, but PET (38-40) or CMR (41-43) with superparamagnetically labeled annexin-V, Gd liposomes with annexin-V coating, and ligand-coated microbubbles (e.g. selectin) have also been used.

A number of laboratories (44-47) including our own have now championed the use of smaller probes to target the other surface phospholipid molecule that is exteriorized in apoptosis: PE. PE is more abundantly expressed (20\% to $25 \%$ of the innerphospholipid bilayer is $\mathrm{PE}$ compared with under $10 \%$ for PS) making it a higher signal target. It can be detected with ${ }^{99 \mathrm{~m}}$ Tc-labeled duramycin, a smallmolecule antibiotic that has been shown to be safe in humans. ${ }^{99 \mathrm{~m}} \mathrm{Tc}$-duramycin is rapidly cleared from the kidneys, resulting in less off-target radiation than ${ }^{99 m}$ Tc-annexin-V (the most commonly used apoptosis imaging agent). We have shown its utility in atheroma (45), MI (46), and chemotherapy-related cardiac damage imaging (47). These studies show that use of duramycin, a well-tested small antibiotic molecule, is safe in humans and might offer better clinical translation of apoptosis imaging.

Given the limitations of annexin- $\mathrm{V}$ imaging, other PS-homing agents targeting the C2A domain of synaptotagmin (48) have been tried in animal models 
FIGURE 2 Magnetic Resonance Molecular Imaging of Cell Death

\section{MYOCARDIAL NECROSIS WITH Gd-TO}

A

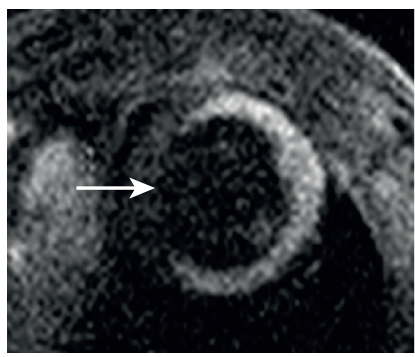

C

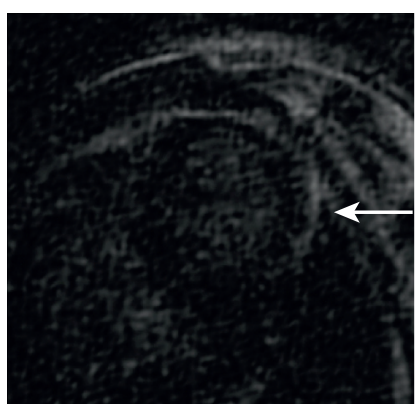

\section{B}

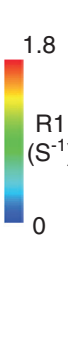

D

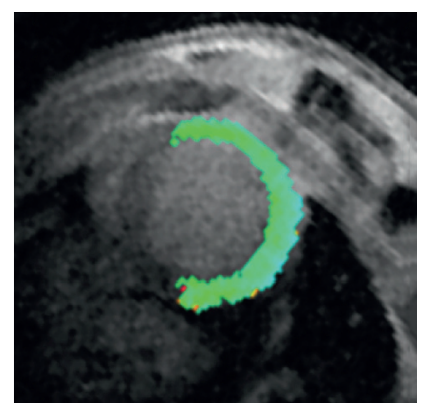

MYOCARDIAL APOPTOSIS WITH ANNEXIN-CLIO
A

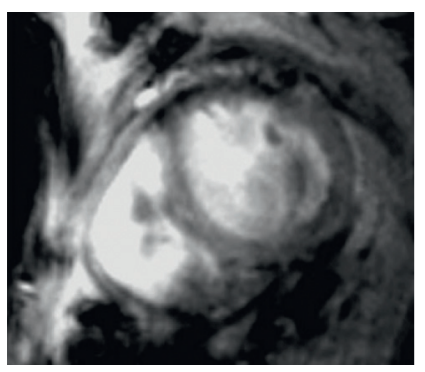

B

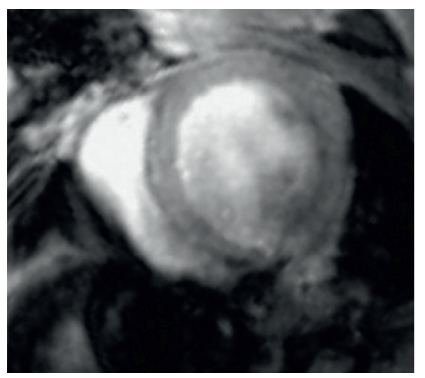

$\mathrm{C}$

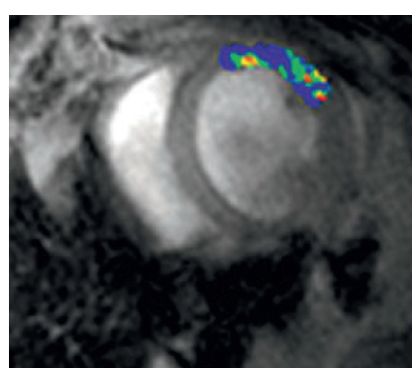

D

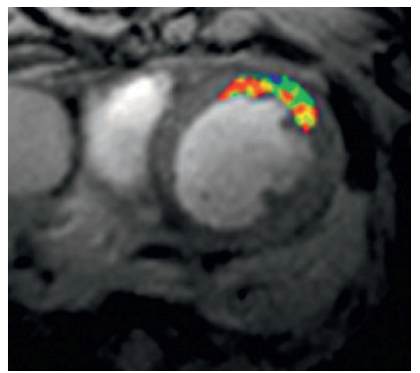

(Top) A deoxyribonucleic acid (DNA)-binding gadolinium chelate (Gd-TO) has been used to specifically detect the exposed DNA in acutely necrotic cells (that have lost their sarcolemmal integrity) in vivo. The figure compares magnetic resonance (MR) images in mice with acute myocardial infarcts injected with either gadolinium fluorochrome thiazole orange (Gd-TO) (A and B) or gadolinium diethylenetriaminepentacetate (Gd-DTPA) (C and D). The mice shown were imaged 18 to $24 \mathrm{~h}$ after infarction. Both mice when labeled with either ${ }^{99 m} \mathrm{Tc}$, nanoparticles $(49,50)$, or probes targeting exposed histones (51). They have not reached human use yet for evaluating cardiac apoptosis.

MR imaging techniques for apoptosis imaging. CMR imaging can detect cell death through scar imaging via LGE, and a combination of mapping techniques $\left(\mathrm{T}_{2}\right.$ mapping for edema, $\mathrm{T}_{1}$ mapping for tissue pathology) combined with LGE can separate reversible from irreversible injury. Gadolinium chelates, which increase $\mathrm{T}_{1}$ relaxation, and iron oxide nanoparticles, which enhance $\mathrm{T}_{2}$ relaxation, are the most commonly used MR imaging contrast agents for apoptotic imaging. CMR using super paramagnetic agents works well to image apoptosis in animal studies $(42,52,53)$. Many different and novel nanoparticles are being studied to image apoptosis without radiation and with better topographic localization $(42,54)$. All still involve a similar paradigm using an apoptosis-sensing ligand (often annexin- $\mathrm{V}$, or more recently, the $\mathrm{C} 2 \mathrm{~A}$ domain of

FIGURE 2 Continued

showed severe wall motion abnormalities in their anterior, lateral, and inferior walls, consistent with extensive infarcts. The arrow in $\mathbf{A}$ points to the uninjured septum. (A and B) Robust accumulation of Gd-TO is seen in the infarct 2 to $3 \mathrm{~h}$ after injection, producing signal hyperintensity and high R1 values. (C) In contrast, 2 to $3 \mathrm{~h}$ after the injection of Gd-DTPA, there is no sign of an increase in signal intensity in the infarct, which is nulled and isointense with the septum. The arrow in $\mathbf{C}$ points to the pericardial fat, which marks the outer border of the infarcted myocardium. (D) R1 map of the mouse injected with Gd-DTPA shows no increase in R1. Thus, Gd-TO is retained in acute myocardial infarcts, whereas GD-DTPA is not. TO not only allows sites of injury to be identified with molecular imaging, it simultaneously exerts an anti-inflammatory and cytoprotective effect. Ergo, TO could be of significant diagnostic and therapeutic (theranostic) utility in a broad range of conditions, including ischemia, trauma, burns, sepsis, and autoimmune disease. Adapted from Huang et al. (17). (Bottom) MR imaging of myocardial apoptosis in live mice after transient coronary artery ligation. Annexin-V-cross-linked iron oxide (AnxCLIO)-Cy5.5 (2 mg Fe/kg) or CLIO-Cy5.5 (2 mg Fe/kg) was injected into the tail vein of the mouse directly after LAD ligation for 30 min. MR imaging was performed on a 9.4-T scanner $24 \mathrm{~h}$ later. Representative frames from FLASH cine acquisitions (TE $4.7 \mathrm{~ms}$ ) are shown: (A) AnxCLIO-Cy5.5 diastolic frame, and (B) CLIO-Cy5.5. Well-defined zones of myocardial hypokinesis were seen in the anterior/anterolateral walls of all mice. However, signal loss, indicative of probe accumulation, was seen only in the hypokinetic zones of mice that had received AnxCLIO-Cy5.5 (A), and not in those that had received CLIO-Cy5.5 (B). In vivo corresponding $\mathrm{T}_{2}$ * maps in mice receiving Anx-CLIO-Cy5.5 (C) and CLIO-Cy5.5 (D). $\mathrm{T}_{2}{ }^{*}$ maps were created in a region-of-interest (ROI) in the myocardium, defined by the zone of hypokinesis. A significant reduction in myocardial $\mathrm{T}_{2}$ * values was seen in the ROI. Modified from Sosnovik et al. (41). 
synaptotagmin-I or a newer PS-binding hexapeptide [TLVSSL]) linked with an imaging molecule (e.g., dextran or citrate-coated, cross-linked magnetic nanoparticles with small iron oxide cores), and studies are mainly in cancer. Apoptosis-sensing nanoparticles have been used for in vivo imaging in the mouse heart with acute ischemia as well as in cardiomyopathy due to Gaq-overexpression $(15,55)$. One of the strengths of using apoptosis-sensing magneto-nanoparticles is the ability to localize apoptosis, determine its extent, and correlate it with morphology and functional consequences (15). This avoids the anatomic and functional uncertainty that come from just using radiolabeled apoptosis-sensing molecules. However, macrophages can eat up nanoparticles; thus, these techniques might be best suited only in cardiac diseases without significant inflammation or macrophage infiltration, which may be a limitation compared to ${ }^{99 \mathrm{~m}} \mathrm{Tc}$-annexin- $\mathrm{V}$ or duramycin imaging. Clinical data is still far away. Proton magnetic resonance spectroscopy and diffusion-weighted MR imaging have been used to detect bulk apoptosis in organs, especially during cancer therapeutics, but have not had extensive studies in the heart.

CMR techniques are rapidly improving, and it is now possible to identify reversible tissue injury from that likely to become irreversible. LGE accurately defines scar and irreversible infarcted myocardium, whereas edema detected by the blackblood $\mathrm{T}_{2}$-weighted techniques in the past and more recently via $T_{1}$ and $T_{2}$ mapping techniques (where free water prolongs both) permit defining area of risk, determining degree of damage, separating reversible versus irreversible parts of infarcted tissue in the subacute phase of acute MI (56-58), and predicting recovery. However, these techniques image large areas of myocardial damage and do not specifically detect apoptosis or other specific cellular forms of cell death. Thus, traditional annexin- $\mathrm{V}$ imaging will still retain a role in specifically imaging apoptotic cell death rather than just identifying dead or potentially survivable areas in the heart.

Potential new techniques. Some newer techniques might hold a promise of better imaging for cell death processes. One such technique is multispectral optoacoustic tomographic imaging, where tissues absorbing near-infrared (NIR) light generate ultrasonic waves that are converted into images of good optical contrast and signal-to-noise ratio. These highresolution cross-sectional or 3-dimensional images have limited depth at this time (a few centimeters at 5 $\mathrm{MHz}$ ), but will surely improve in the near future. Tagging apoptotic probes, like C2A domain of synaptotagmin-I, with NIR fluorophores produces imaging tracers that can bind PS on apoptotic cell surfaces and can be used to image cell death within an entire volume, say in a tumor. Measurements made at several NIR wavelengths can also enable realtime imaging of chromophores. Cancer applications abound (59), but multispectral optoacoustic tomography has been used in imaging MI (60) and for detecting vulnerable plaque in coronaries, carotid and peripheral arteries, when coupled with intravascular catheters $(61,62)$.

\section{NONEXTERIORIZED TARGETS FOR IMAGING APOPTOSIS AND CELL SURVIVAL}

The cancer data contains a fair amount of emerging publications focusing on nonexteriorized targets, such as executioner caspases and mitochondrial membrane potential imaging. There is nearly no published data about this for noninvasive cardiac imaging, and these will be briefly addressed only to describe what may be possible in future for cardiac imaging.

MEMBRANE INTEgRITY TARgETS. Mitochondrialtargeted myocardial tracers, which evaluate mitochondrial membrane integrity, voltage gradients, and viability, are under rapid development and might allow one to study metabolism and early apoptotic changes, and predict viability better, especially when used with hybrid imaging (e.g., PET-CT or PET-MR). The outer mitochondrial membrane is an important permeability barrier between the mitochondrion and the cytoplasm and regulates the coupling of cellular respiration and apoptosis. The mitochondrial inner membrane creates transmembrane polarity (negative inside) and is needed for proper function and to protect against apoptosis.

Some lipid permeable compounds aggregate in cell cytoplasm and mitochondria in a voltage-dependent manner and can thus act as a voltage sensor, because uptake is dependent on maintenance of adequate mitochondrial voltage. Mitochondrial membrane potential is reduced in apoptosis, and this sine qua non acts as a durable fingerprint of cellular apoptosis and is associated with decreased uptake of such compounds (63). This can be tracked with PET tracers, but as yet there is only very preliminary data on its ability to track cardiac apoptosis (64). ${ }^{99 m} \mathrm{Tc}$ methoxyisobutylisonitrile (MIBI) accumulates in mitochondria with the highest negative potential, which correlates with healthy mitochondria and intact membrane permeability (65). A lack of 99m Tc-MIBI uptake can predict cells with damaged mitochondrial membrane potential; this imaging technique has been used to predict cancer cells that 
FIGURE 3 Images of Unstable Atherosclerotic Carotid Artery Lesions Obtained With Radiolabeled Annexin-V

A

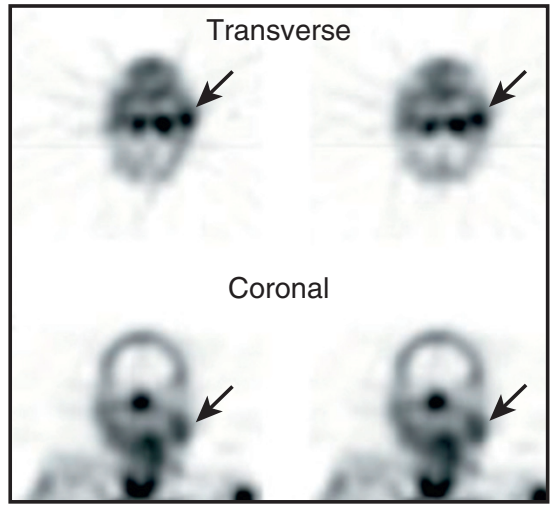

C

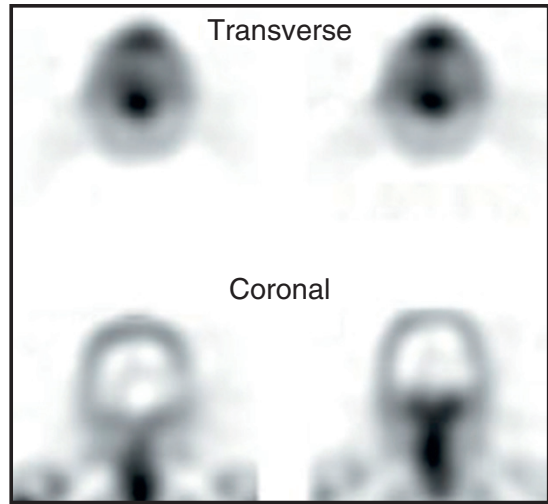

B

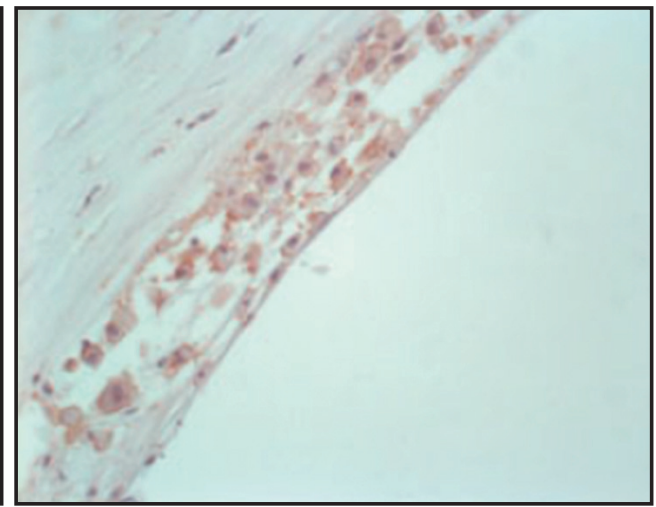

$\mathrm{D}$

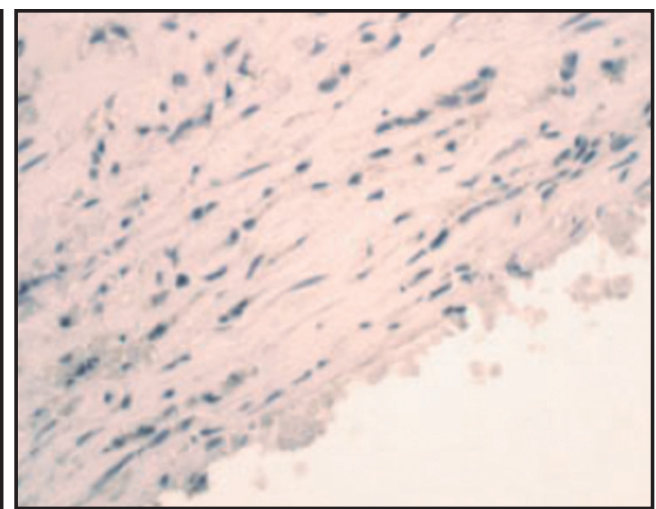

(A) Transverse and coronal views obtained by single-photon emission computed tomography (SPECT) in Patient 1, who had a left-sided transient ischemic attack (TIA) 3 days before imaging. Although this patient had clinically significant stenosis of both carotid arteries, uptake of radiolabeled annexin A5 is evident only in the culprit lesion (arrows). Histopathological analysis of an endarterectomy specimen from Patient 1 (B) (polyclonal rabbit anti-annexin A5 antibody, $\times 400$ ) shows substantial infiltration of macrophages into the neointima, with extensive binding of annexin A5 (brown). In contrast, SPECT images of Patient 3 (C), who had a right-sided TIA 3 months before imaging, do not show evidence of annexin A5 uptake in the carotid artery region on either side. Doppler ultrasonography revealed a clinically significant obstructive lesion on the affected side. Histopathological analysis of an endarterectomy specimen from Patient 3 (D) (polyclonal rabbit anti-annexin A5 antibody, $\times 400$ ) shows a lesion rich in smooth-muscle cells, with negligible binding of annexin A5. Reprinted with permission from Kietselaer et al. (33). ANT = anterior; $L=$ left.

are unlikely to respond to chemotherapy, but has not been investigated in cardiac cell death.

There are other agents under development that might overcome the limitations of MIBI-like compounds. Lipophilic cations, like the positively charged ${ }^{18} \mathrm{~F}$-labeled triphenyl phosphonium probes can be used to assess apoptosis-related mitochondrial dysfunction by detecting the loss of mitochondrial membrane potential $(\Delta \Psi \mathrm{m})$ (63). Further improvements in triphenyl phosphonium chemistry will provide clinically usable mitochondrial voltage as well as viability probes (66). Rhodamine dyes have also been used as ${ }^{18} \mathrm{~F}$-labeled probes directly evaluating the integrity loss of mitochondrial membrane potential, because they also accumulate in the mitochondria in proportion to membrane potential (67). Robust clinical studies are as yet awaited.

EXECUTIONER CASPASE TARGETS. Many of the steps that can be imaged in the apoptotic process (Central Illustration), although showing promise in cancer imaging and elsewhere, have not reached maturity for noninvasive imaging of cardiac apoptosis. Imaging the intracellular cell death executioner machinery like caspases 3 or 7 sounds 
FIGURE 4 Clinical Imaging of Myocardial Infarction
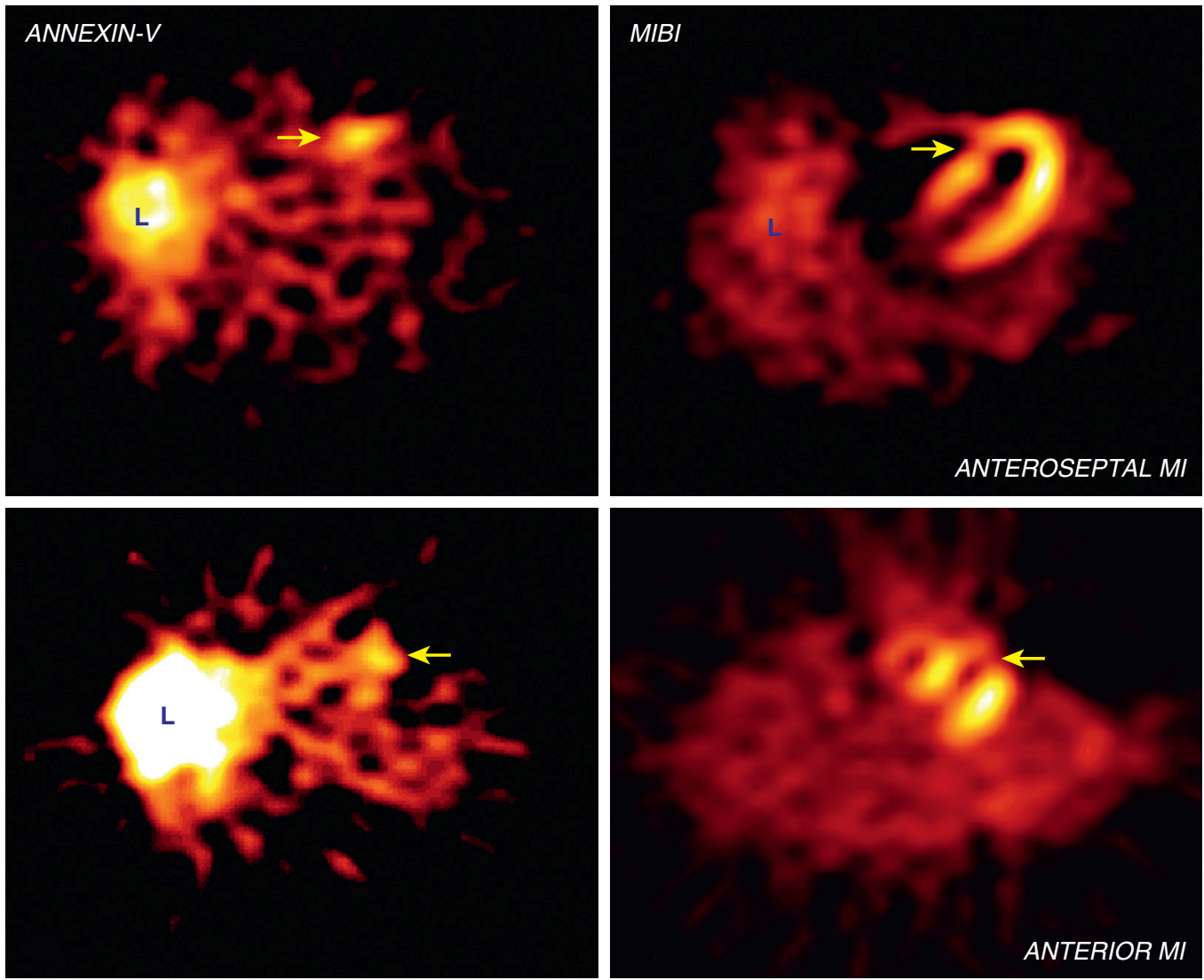

Myocardial apoptosis has clinically been evaluated by indium-111-labeled annexin- $\mathrm{V}$, an endogenous protein that targets abundant surface exposure of phosphatidylserine (PS), normally a resident of the inner lamella of sarcolemma. Exteriorized PS mediates phagocytosis of apoptotic cells by macrophages. Annexin-V avidly binds to PS with nanomolar affinity. Annexin uptake is distinctly seen in the anteroseptal (top, left) and antero-apical (bottom, left) regions. Annexin-V uptake clearly conforms to sestamibi-detected zones of myocardial perfusion deficit (right, top and bottom). The transverse tomographic images were obtained $18 \mathrm{~h}$ after MI, and MIBI images after 6 weeks. High liver uptake might occasionally interfere with annexin uptake in inferior myocardial regions, a problem that is being addressed with PE-seeking duramycin targeting of apoptosis. Adapted from Hofstra et al. (2). L = liver.

attractive, but is beset with a number of issues including the need to have either cell permeable probes (68) or a cell with increased membrane permeability. Caspase imaging may not be specific, and caspase activation is dynamic, which makes it difficult to quantitatively time and target a particular marker caspase. ${ }^{11} \mathrm{C}$ or ${ }^{18} \mathrm{~F}$-labeled small molecule caspase inhibitor isatins can be imaged with PET to detect caspase activity, as shown in hepatic cells (69). Other probes need to be activated by such intracellular targets and the reporter molecules (70), but may be limited due to difficulties in uptake or internalization, or nonspecific cleavage by other proteases (71). Caspases may not be definitively associated with cell death, which makes imaging cell death a bit challenging $(72,73)$. Finally, such imaging probes are often expelled through P-glycoprotein transmembrane efflux pumps (74), which makes imaging caspases cumbersome. Many probes are based on optical imaging (71), but nuclear imaging-based probes are soon to come (69). Although some have been tested in humans (75), they are still far from meaningful use. No significant body of cardiac imaging exists for any of these strategies, but recent study showed that a caspase-3-PET tracer, ${ }^{18} \mathrm{FWC}-4-116$, imaged caspase activity during myocardial apoptosis in a rat IR model, suggesting the potential to monitor caspase activity during myocardial injury (76). 
FIGURE 5 Myocardial Apoptosis in Heart Failure

A

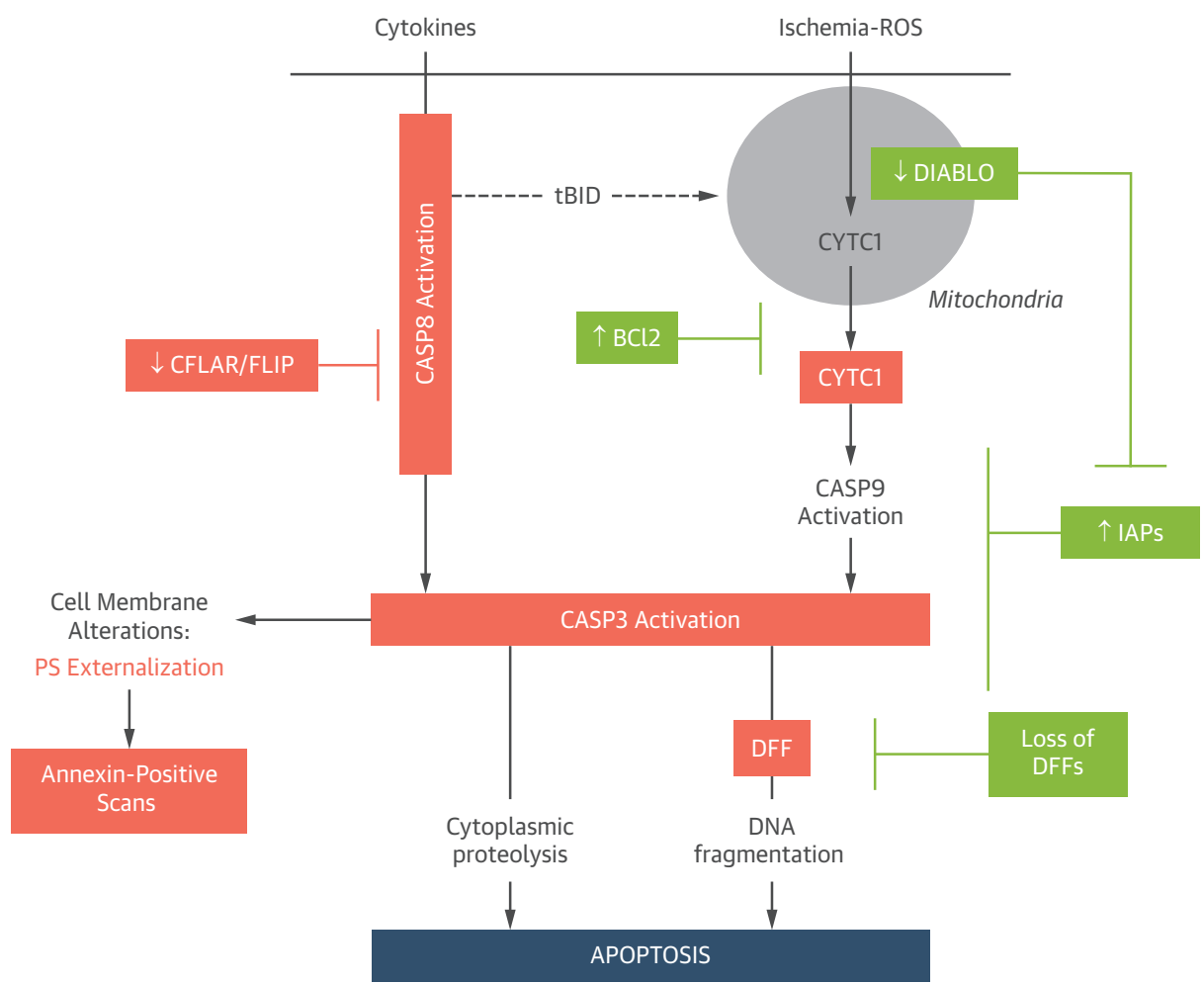

Myocardial apoptosis plays an important role in heart failure progression and is amenable to molecular imaging. (A) Molecular basis of apoptosis imaging in heart failure. Unlike acute myocardial insults, such as in myocardial ischemia and inflammation, the slow inexorable process of apoptosis that is mediated by proapoptotic intracellular signaling (pink) allows concurrent up-regulation of antiapoptotic (green) factors. Even after abundant release of cytochrome $\mathrm{c} 1$ release from mitochondria into the cytoplasmic compartment, apoptosis is largely prevented by the simultaneous presence of the IAPs and Bcl2 family of proteins. Uninhibited activation of caspase- 8 and residual activated caspase- 9 lead to low-level caspase-3 activation. There is contractile proteolysis and vacuole formation. DNA fragmentation is usually prevented. The residual activated caspase-3 induces cell membrane changes and helps exposure of phospholipids such as PS and PE. The greater the intracellularly activated caspase-3 (pro-apoptotic mediators stronger than antiapoptotic factors), the more likelihood of a positive annexin-V scan, and the less likelihood of favorable clinical outcome. Adapted from Kietselaer BL, Reutelingsperger $\mathrm{CP}$, Boersma $\mathrm{HH}$, et al. Noninvasive detection of programmed cell loss with ${ }^{99 m}$ Tc-labeled annexin V5 in heart failure. J Nucl Med 2007;48:562-7.

Continued on the next page

\section{TRANSLATIONAL OPPORTUNITIES IN IMAGING FOR APOPTOSIS}

CLINICAL AND EXPERIMENTAL DATA. Unlike cancer, where cell death is a desirable endpoint, cell death, especially of the apoptotic form, is a common but undesirable occurrence in cardiac diseases, given its limited potential for regeneration. Many cardiac diseases have ongoing low-level apoptosis that is thought to underlie myocyte loss and chronic dysfunction. This hypothesis remains controversial (77) and is not entirely proven in human studies, but it seems quite convincing in animal experiments, where apoptotic machinery was manipulated to induce a pro-apoptotic milieu.
AtHerosclerosis. Atherosclerotic plaque rupture is associated with the majority of the acute coronary events (Figure 3 ). The high-risk plaque precursors of plaque rupture are usually extensively positively remodeled to carry large lipid cores that are separated from lumen by a very thin fibrous cap. Ongoing apoptosis of the plaque microconstituents, such as macrophages and smooth muscle cells, contributes to core enlargement and cap thinning and perpetuates plaque instability $(78,79)$. Plaque stability is, among other things, influenced by the ability of macrophages in plaque to ingest and clear apoptotic bodies (i.e., "efferocytosis"); defective efferocytosis facilitates formation of a necrotic core, because uncleared apoptotic bodies swell and shed their 
B1

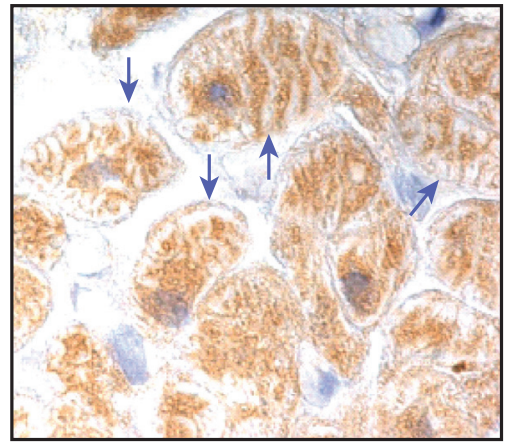

B4
B2

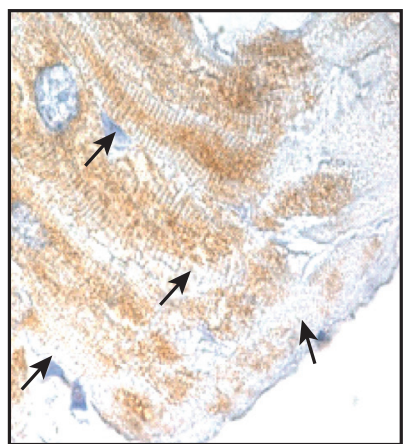

B5
B3
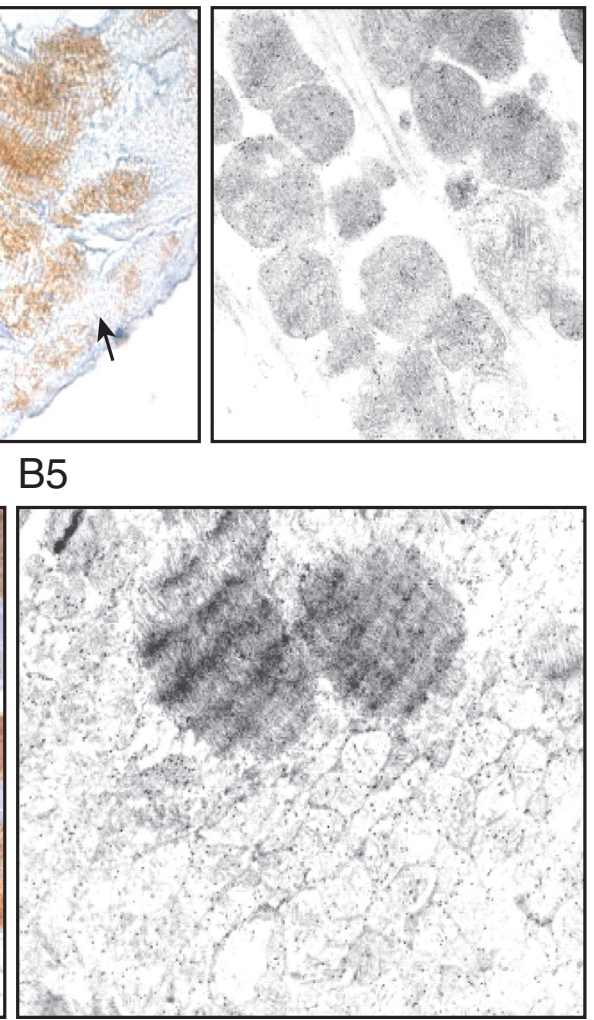

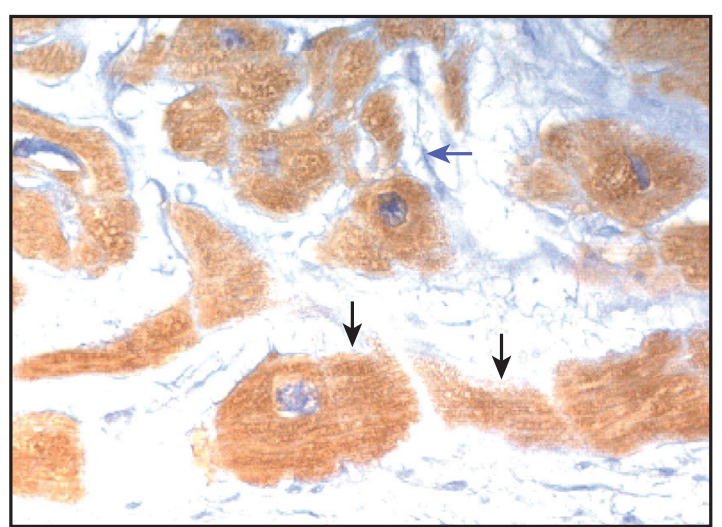

(B) Cytochrome c1 distribution and nuclear morphology in control and cardiomyopathic hearts. Light microscopy immunohistochemistry with anticytochrome $\mathrm{c}$ antibody in myocardial specimens $(\times 100)$ revealed significant differences in distribution of cytochrome $\mathrm{c} 1$ and nuclear morphology. (B1) Transverse section of control heart. The mitochondria-specific immunostain assumes a typical zebra-like distribution pattern (arrows). (B2) In longitudinal sections of a control heart, the easily recognizable sarcomeres are not stained (arrows). (B3) Immunoelectron microscopy of a normal heart documents mitochondria decorated by the gold-conjugated anticytochrome c antibody particles ( $\times 56,000)$. (B4) Light microscopy of the dilated cardiomyopathy sample shows that the anticytochrome $\mathrm{c}$ antibody has stained both mitochondrial and nonmitochondrial structures, including sarcomeres $(\times 100)$. The same section contains both longitudinally (black arrows) and transversally (blue arrow) cut myocytes. Nuclei are morphologically nonapoptotic. (B5) The immunoelectron microscopy shows that anticytochrome $\mathrm{c} 1$ antibody decorate both mitochondria and nonmitochondrial structures, including sarcomeres $(\times 26,000)$. B1, B2, and B4 show staining with avidinbiotin complex; B3 and B5 show staining with uranyl acetate and lead citrate. Adapted from Haider N, Arbustini E, Gupta S, et al. Concurrent upregulation of endogenous proapoptotic and antiapoptotic factors in failing human hearts. Nat Clin Pract Cardiovasc Med 2009;6:250-61.

Continued on the next page

contents to damage surrounding tissues. Therefore, expansion of necrotic core is likely the consequence of accelerated macrophage apoptosis and ineffective efferocytosis $(80,81)$. It has been suggested that apoptosis may help promote thrombosis on ruptured plaques (82).

Atherosclerosis in the carotid artery, abdominal aorta, and coronary arteries has been investigated for apoptosis with noninvasive methods. SPECT-CT imaging with either ${ }^{99 \mathrm{~m}} \mathrm{Tc}$-labeled annexin- $\mathrm{V}$ or, more recently, ${ }^{99 \mathrm{~m}} \mathrm{Tc}$-radiolabeled duramycin from our laboratory (45) has been used most often for targeting apoptosis and correlates well with histological findings (83) of apoptosis in macrophages (84) or smooth muscle cells (85) in the carotid arteries, abdominal aorta, as well as the coronary arteries. Apoptosis imaging has also been used to noninvasively determine the effects of plaquepassivating therapies (86). Human studies are fewer, but may be promising to differentiate stable from unstable plaques as in patients with stroke or transient ischemic attack (33). Such studies offer hope of being able to noninvasively monitor high-risk plaques and the effect of therapy. 
FIGURE 5 Continued
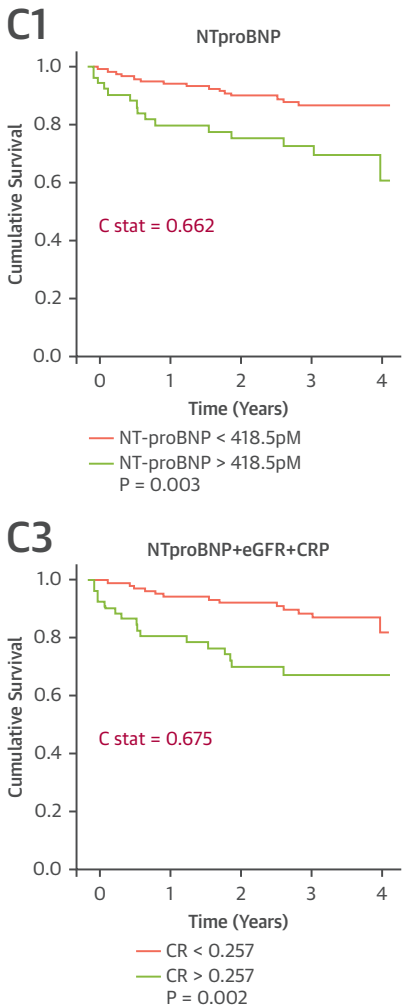

\section{C5 Con $=0.47 \pm 0.29$ v.}

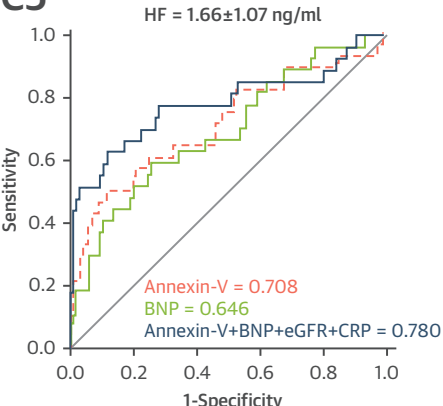

Predictors, Age, NYHA, Annexin-V, NT-proBNP $\mathrm{S}=1.4 \pm 0.8 \mathrm{~V}$

$\mathrm{NS}=2.5 \pm 1.7 \mathrm{ng} / \mathrm{m}$

$\mathrm{HR}=1.728[1.389-2.150]$

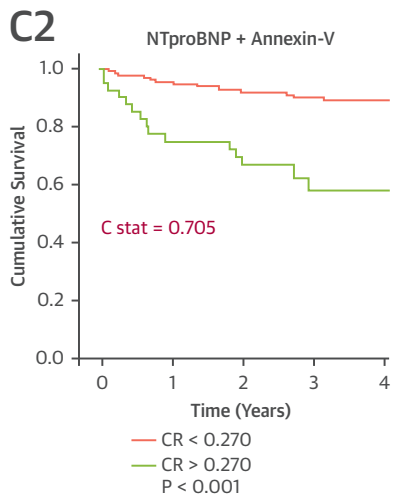

C4

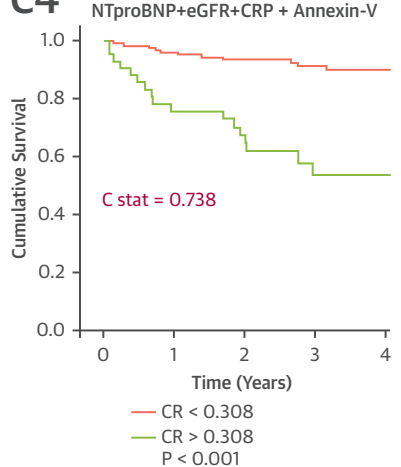

C6

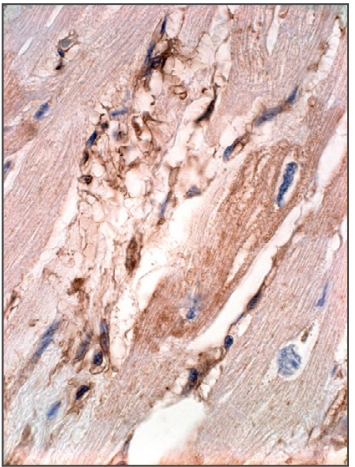

(C) Incremental value of circulating annexin- $V$ over conventional biomarkers for predicting mortality in heart failure. Circulating annexin- $V$ levels are increased in heart failure and can be measured for prognostication. The data are developed from 180 heart failure patients and 20 control subjects, wherein 20 heart failure deaths occurred during follow-up. Kaplan-Meier plots (C1 to C4) are shown based on the optimal cut-off values derived from receiver-operating characteristic curve analysis (C5) for N-terminal pro-B-type natriuretic peptide (NT-proBNP) (C1), annexin-V + NT-proBNP (C2), NT-proBNP + estimated glomerular filtration rate (eGFR) + C-reactive protein CRP (C3), and annexin-V + NT-proBNP + eGFR + CRP (C4) to predict mortality in patients with heart failure. CR = combined risk. (C5) Receiver-operating characteristic curve analysis to predict 3-year mortality in patients with heart failure is presented for $\mathrm{N}$-terminal pro-B-type natriuretic peptide, eGFR, and CRP (solid line), annexin-V alone (dashed line), and annexin-V combined with NT-proBNP, eGFR, and CRP (dotted line). (C6) A myocardial sample obtained from a nonischemic cardiomyopathy patient was investigated for in situ annexin- $V$ localization by direct immunostaining with antiannexin- $V$ antibody. Substantial localization of annexin- $V$ is seen in the interstitium and intracellularly. This suggests that annexin- $\mathrm{V}$ is increasingly produced in myocardium (as also other organs, data not shown) and hides cell surface apoptotic signals to protect myocytes from phagocytosis. The annexin- $\mathrm{V}$ levels are expected to represent long-term status of myocardial pathology, unlike acute markers such as NT-proBNP. Modified from Schurgers LJ, Burgmaier M, Ueland T, et al. Circulating annexin A5 predicts mortality in patients with heart failure. J Intern Med 2016;279:89-97. 
FIGURE 6 Apoptosis Imaging in Transplant Rejection
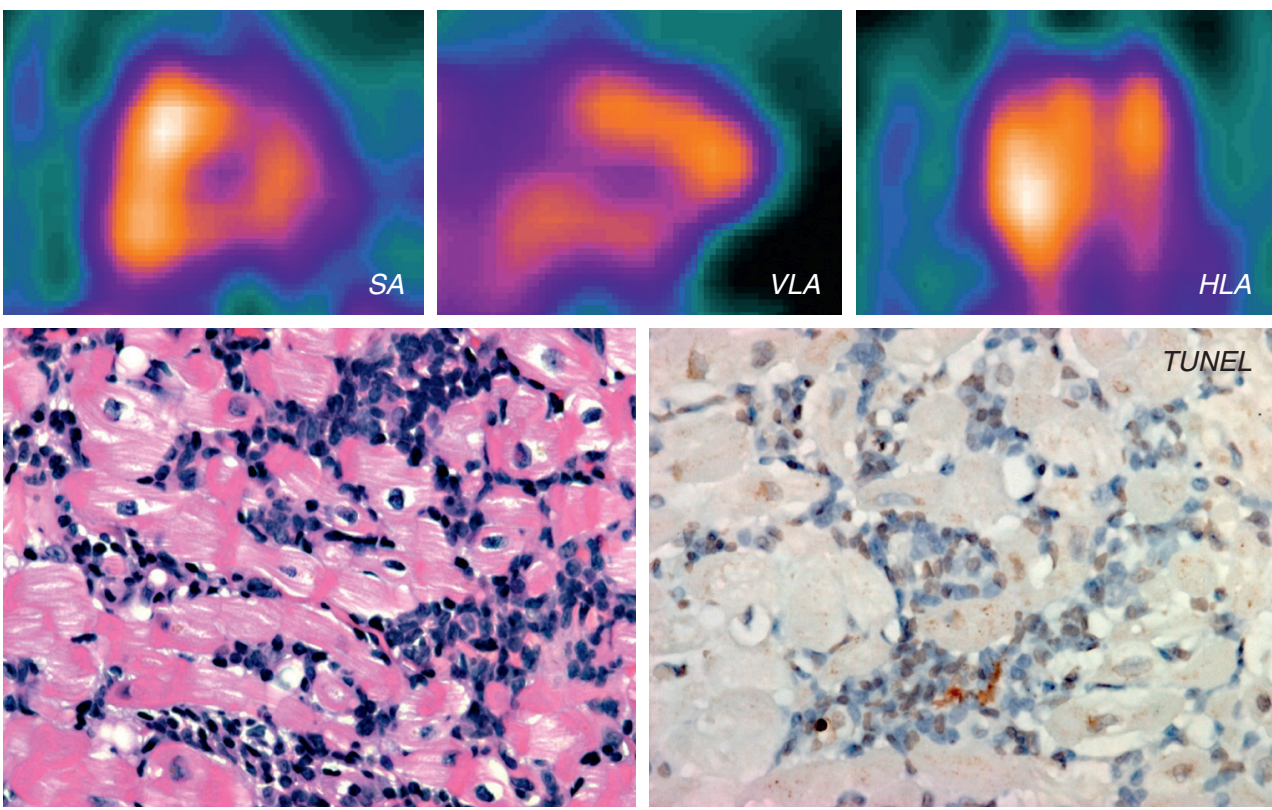

Annexin-V imaging 9 months after orthotopic heart transplantation. (Top) Single-photon emission computed tomography (SPECT) imaging $3 \mathrm{~h}$ after intravenous injection of radiolabeled annexin- $\mathrm{V}$ demonstrated multifocal myocardial uptake of radiotracer. Smoothening of the images and cardiac SPECT processing in the short axis (SA), vertical long axis (VLA), and horizontal long axis (HLA) revealed myocardial perfusion scan-like images with diffuse uptake in whole myocardium, suggesting apoptosis in the myocardium. (Bottom) Right ventricular EMB was performed within $24 \mathrm{~h}$ of the scan that revealed ISHLT grade $2 \mathrm{R}$ (previously $3 \mathrm{~A} / 4$ ) rejection characterized by lymphomononuclear cell infiltration and at least 2 foci of myocyte necrosis; 1 focus of myocyte necrosis associated with intense inflammation is shown (H\&E staining; magnification, $\times 40$, left). Positive TUNEL staining (brown) was observed in occasional myocytes, lymphomononuclear cells, and endothelial cells (right).

MYOCARDIAL ISCHEMIA AND MI. Apoptosis has reported in myocardial ischemia, and more prominently in the border zone of MI with reperfusion injury (87) (Figure 4). Coronary artery occlusion with or without reperfusion was one of the initial models of edema cell death (88); both apoptosis and necrosis occur mainly in the infarct zone, and to a lesser degree in the peri-infarct zone as well as in the remodeled remote myocardium in a time and stimulus magnitude-dependent manner (89). Apoptosis starts within minutes of ischemia and precedes necrosis by many hours after MI. Apoptosis persists long after the necrotic event, and slow ongoing apoptotic cell loss over years is thought to be responsible for ventricular remodeling and progression of heart failure $(90,91)$. Modulating apoptosis reduces infarct size (91) and might be a way to attenuate left ventricular dysfunction in post-infarct patients (92). There are animal data that attenuating apoptosis in a number of ways can attenuate infarct size, ventricular remodeling, and eventual heart failure. Apoptosis is detectable in human MI (2) (Figure 4), but as yet there is no human data convincingly showing the benefit of antiapoptotic intervention in human acute MI. Necroptosis is now being recognized in ischemiareperfusion injury in the heart, kidney, and brain, and early studies show that inhibiting it seems to be beneficial (7).

Apoptosis imaging in acute MI or ischemiareperfusion injury has mainly employed ${ }^{99 \mathrm{~m}_{\mathrm{Tc}}}$ annexin-V with SPECT to target PS, CMR probes to target DNA fragments, and less commonly, some other strategies $(15,16,33,93,94)$. Translation into human studies has been slow due to a number of issues, and introduction of small molecule agents like duramycin might change the field. Preliminary studies using ${ }^{99 m}$ Tc-labeled annexin- $\mathrm{V}$ SPECT imaging demonstrate the ability to show and possibly size infarcted areas in patients with MI undergoing primary PCI (2,95). ${ }^{99 m}$ Tc-annexin-V uptake matched the MI location; the time course suggested early apoptosis that declined with time, and SPECT defect 6 weeks later matched areas of ${ }^{99 \mathrm{~m}} \mathrm{Tc}$-annexin- $\mathrm{V}$ uptake. Future improvements in noninvasive apoptosis 
imaging might allow for rapid triage of patients with the highest risk for cell death as well as map the benefit of therapeutic intervention.

\section{APOPTOSIS IN HEART FAILURE AND CARDIAC TRANSPLANTATION}

Apoptosis in human heart failure was first described by Narula et al. (96) and was quickly confirmed by other groups (97) (Figures 5 and 6). Chronic ongoing apoptosis may have a role in remodeling and in the subsequent development of heart failure both in post-infarct ischemic or nonischemic cardiomyopathy (96-98). However, its prevalence is low $(<0.1 \%$ terminal deoxynucleotidyl transferase dUTP nick-end labeling-positive cells) (97), and smoldering lowlevel apoptotic activity in failing human hearts (97) is thought to contribute to cumulative myocyte loss and eventual progression of heart failure (98). Mitigation of apoptosis during genetic manipulation or pharmacological apoptotic inhibition $(99,100)$ can be effectively imaged noninvasively, but animal models have higher levels of apoptosis than shown in chronic human heart failure. This might pose difficulties in translating animal data into humans, which will be necessary if apoptosis imaging is to have fundamental clinical utility. Because chronic ongoing apoptosis is a tussle between concurrent upregulation of intracellular pre- and anti-apoptotic mediators, cardiomyocytes demonstrate a strong survival instinct (6) that renders myocytes into a hibernating mode. These cells exist as inactive or zombie cells (6) and may recover upon elimination of etiologic agent or providing antiapoptotic support (99-101). Tracking apoptotic death and predicting cell survival in chronic heart failure will be an exciting frontier in heart failure imaging.

Apoptosis has been demonstrated in myocarditis (102) in some but not all studies (103) and correlates with heart failure death but not sudden cardiac death, suggesting its role in fatal heart failure. Human studies of enterovirus-related myocarditis biopsy specimens confirm apoptosis that correlated with viral load and clinical severity (104). Antiapoptotic agents decrease the severity of myocarditis in animal models, but the relation in human disease, including human immunodeficiency virus cardiomyopathy, is unclear. Imaging has shown the presence of histology-proven apoptosis in myocarditis $(105,106)$ and doxorubicin-induced cardiac damage (107). Apoptosis (programmed cell death) is a feature of clinical and experimental immunological myocarditis in the form of transplant rejection (108). ${ }^{99 m} \mathrm{Tc}$ annexin- $\mathrm{V}$ shows uptake colocalizing to apoptosis in rodent myocarditis $(105,109)$. Human data is lacking, but strikingly positive animal data offers the promise that such imaging might detect early damage, stratify patients for advanced therapies, and allow serial monitoring of damage and improvement. Early data show such promise in cardiac transplant rejection, which has some similarities with inflammatory cardiac dysfunction. Human studies in a small number of subjects post-cardiac transplant showed the utility of

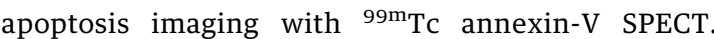
Although promising, this technique still lacks adequate specificity $(3,110)$. New tracers might improve this delay to translation.

\section{CONCLUSIONS}

Cell death is an attractive target for noninvasive imaging with an aim to understand pathophysiology, diagnose and predict myocyte loss, track disease activity to potentially modulate course, and evaluate response to therapeutic intervention. Apoptosis seems to be the most promising target for imaging cell death that can be reversible under certain conditions and may be modulated with present and future interventions. Although necrosis and to a certain extent, autophagy can also be imaged, the utility of such imaging is less clear. Multiple strategies, often involving an apoptosis-sensing ligand paired with an imageable reporter molecule (nuclear, optical, or CMR-based), have been designed to target multiple intermediate steps in the apoptosis cascade. Animal studies are more promising, showing definitive proof for existence of significant apoptosis in many different cardiac diseases, contribution of apoptosis to progression of disease, and benefit of antiapoptotic modulation. Human studies evaluating cardiac apoptosis have involved only very few patients, are more than a decade old, and remain inconclusive, but they show feasibility of monitoring apoptosis. However, there is a lot of innovative activity in this field, including the development of new imaging probes that might be conducive to multimodal hybrid imaging systems and greater use of nanoparticles that promise theranostic paradigms (111). These technologies offer significant promise, especially in tracking apoptosis in cancer patients, and many are in phase $2 / 3$ trials; they are likely to move the field forward with eventual migration to cardiac diseases.

ADDRESS FOR CORRESPONDENCE: Dr. Jagat Narula, Icahn School of Medicine at Mount Sinai, One Gustave L. Levy Place, New York, New York 10029. E-mail: narula@mountsinai.org. 


\section{REFERENCES}

1. Hotchkiss RS, Strasser A, McDunn JE, Swanson PE. Cell death. N Engl J Med 2009;361: 1570-83.

2. Hofstra $L$, Liem $I H$, Dumont $E A$, et al. Visualisation of cell death in vivo in patients with acute myocardial infarction. Lancet 2000;356:209-12.

3. Narula J, Acio ER, Narula $N$, et al. Annexin-V imaging for noninvasive detection of cardiac allograft rejection. Nat Med 2001;7:1347-52.

4. Galluzzi L, Vitale I, Abrams JM, et al. Molecular definitions of cell death subroutines: recommendations of the Nomenclature Committee on Cell Death 2012. Cell Death Differ 2012;19:107-20.

5. Lemasters JJ, Nieminen AL, Qian $T$, et al. The mitochondrial permeability transition in cell death: a common mechanism in necrosis, apoptosis and autophagy. Biochim Biophys Acta 1998;1366: 177-96.

6. Narula J, Haider N, Arbustini E, Chandrashekhar Y. Mechanisms of disease: apoptosis in heart failure-seeing hope in death. Nat Reviews Cardiol 2006;3:681-8.

7. Weinlich R, Oberst A, Beere HM, Green DR. Necroptosis in development of inflammation and disease. Nat Rev Mol Cell Biol 2017;18:127-36.

8. Nishida K, Yamaguchi O, Otsu K. Crosstalk between autophagy and apoptosis in heart disease. Circ Res 2008;103:343-51.

9. Nikoletopoulou V, Markaki M, Palikaras K, Tavernarakis N. Crosstalk between apoptosis, necrosis and autophagy. Biochim Biophys Acta 2013; 1833:3448-59.

10. Khaw BA, Narula J. Non-invasive detection of myocyte necrosis in myocarditis and dilated cardiomyopathy with radiolabelled antimyosin. Eur Heart J 1995;16 Suppl 0:119-23.

11. Corbett JR, Lewis $M$, Willerson JT, et al. 99mTc-pyrophosphate imaging in patients with acute myocardial infarction: comparison of planar imaging with single-photon tomography with and without blood pool overlay. Circulation 1984;69: 1120-8.

12. Narula J, Petrov A, Pak KY, Lister BC, Khaw BA. Very early noninvasive detection of acute experimental nonreperfused myocardial infarction with 99mTc-labeled glucarate. Circulation 1997;95: 1577-84.

13. Narula J, Southern JF, Dec GW, et al. Antimyosin uptake and myofibrillarlysis in dilated cardiomyopathy. J Nucl Cardiol 1995;2:470-7.

14. Tahara $\mathrm{N}$, Zandbergen $H R$, de Haas $H J$, et al. Noninvasive molecular imaging of cell death in myocardial infarction using 111In-GSAO. Sci Rep 2014;4:6826.

15. Sosnovik DE, Garanger E, Aikawa $E$, et al. Molecular MRI of cardiomyocyte apoptosis with simultaneous delayed-enhancement MRI distinguishes apoptotic and necrotic myocytes in vivo: potential for midmyocardial salvage in acute ischemia. Circ Cardiovasc Imaging 2009;2:460-7.

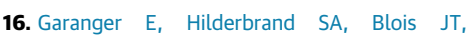
Sosnovik DE, Weissleder R, Josephson L. A DNA- binding Gd chelate for the detection of cell death by MRI. Chem Commun (Camb) 2009;29:4444-6.

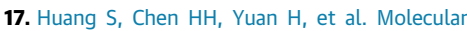
MRI of acute necrosis with a novel DNA-binding gadolinium chelate: kinetics of cell death and clearance in infarcted myocardium. Circ Cardiovasc Imaging 2011:4:729-37.

18. Yoshihara HA, Bastiaansen JAM, Berthonneche $C$, et al. An intact small animal model of myocardial ischemia-reperfusion: Characterization of metabolic changes by hyperpolarized 13C-MR spectroscopy. Am J Physiol Heart Circ Physiol 2015;309: H2058-66.

19. Cunningham $C H$, Lau JYC, Chen $A P$, et al, Hyperpolarized 13C-metabolic MRI of the human heart: initial experience. Circ Res 2016;119: 1177-82.

20. Miller JJ, Lau AZ, Nielsen PM, et al. Hyperpolarized [1,4-13C2]fumarate enables magnetic resonance-based imaging of myocardial necrosis. J Am Coll Cardiol Img 2017 Dec 9 [E-pub ahead of print].

21. Leuschner F, Nahrendorf M. Molecular imaging of coronary atherosclerosis and myocardial infarction: considerations for the bench and perspectives for the clinic. Circ Res 2011;108: 593-606.

22. Tanimoto $T$, Parseghian $M H$, Nakahara $T$, et al. Cardioprotective effects of HSP72 administration on ischemia-reperfusion injury. J Am Coll Cardiol 2017;70:1479-92.

23. Duprez L, Takahashi N, Van Hauwermeiren F, et al. RIP kinase-dependent necrosis drives lethal systemic inflammatory response syndrome. Immunity 2011;35:908-18.

24. Vandenabeele $P$, Galluzzi L. Vanden Berghe $T$, Kroemer G. Molecular mechanisms of necroptosis: an ordered cellular explosion. Nat Rev Mol Cell Biol 2010;11:700-14.

25. Karunakaran D, Geoffrion M, Wei L, et al. Targeting macrophage necroptosis for therapeutic and diagnostic interventions in atherosclerosis. Sci Adv 2016;2:e1600224.

26. Lavandero $S$, Chiong M, Rothermel BA, Hill JA. Autophagy in cardiovascular biology. J Clin Invest 2015;125:55-64.

27. Gottlieb RA, Andres AM, Sin J, Taylor DP. Untangling autophagy measurements: all fluxed up. Circ Res 2015;116:504-14.

28. Chen $\mathrm{HH}$, Mekkaoui $\mathrm{C}$, Cho $\mathrm{H}$, et al. Fluorescence tomography of rapamycin-induced autophagy and cardioprotection in vivo. Circ Cardiovasc Imaging 2013;6:441-7.

29. Laufer EM, Winkens MHM, Narula J, et al. Molecular imaging of macrophage cell death for the assessment of plaque vulnerability. Arterioscler Thromb Vasc Biol 2009;29:1031-8.

30. Smith BA, Smith BD. Biomarkers and molecular probes for cell death imaging and targeted therapeutics. Bioconjug Chem 2012;23: 1989-2006.
31. Nguyen QD, Challapalli A, Smith G, et al. Imaging apoptosis with positron emission tomography: 'bench to bedside.'. Eur J Cancer 2012;48: 432-40.

32. Kenis $H$, Zandbergen $H R$, Hofstra $L$, et al. Annexin A5 uptake in ischemic myocardium: demonstration of reversible phosphatidylserine externalization and feasibility of radionuclide imaging. J Nucl Med 2010;51:259-67.

33. Kietselaer $B L$, Reutelingsperger $C P$, Heidendal GA, Daemen MJ, Mess WH, Hofstra L, Narula J. Noninvasive detection of plaque instability with use of radiolabeled annexin A5 in patients with carotid artery atherosclerosis. N Engl J Med 2004;350: 1472-3.

34. Sarai $M$, Hartung $D$, Petrov $A$, et al. Broad and specific caspase inhibitor-induced acute repression of apoptosis in atherosclerotic lesions evaluated by radiolabeled annexin A5 imaging. J Am Coll Cardiol 2007;50:2305-12.

35. Dumont EA, Hofstra $L$, van Heerde WL, et al. Cardiomyocyte death induced by myocardial ischemia and reperfusion: measurement with recombinant human annexin- $\mathrm{V}$ in a mouse model. Circulation 2000;102:1564-8.

36. Blankenberg FG, Katsikis PD, Tait JF, et al. In vivo detection and imaging of phosphatidylserine expression during programmed cell death. Proc Natl Acad Sci U S A 1998;95:6349-54.

37. Sarda-Mantel L, Michel JB, Rouzet F, et al. $(99 m) T c-a n n e x i n ~ V$ and (111)In-antimyosin antibody uptake in experimental myocardial infarction in rats. Eur J Nucl Med Mol Imaging 2006;33: 239-45.

38. Grierson JR, Yagle KJ, Eary JF, et al. Production of [F-18]fluoroannexin for imaging apoptosis with PET. Bioconjug Chem 2004;15:373-9.

39. Keen HG, Dekker BA, Disley L, et al. Imaging apoptosis in vivo using 124l-annexin $\mathrm{V}$ and PET. Nucl Med Biol 2005:32:395-402.

40. Cauchon N, Langlois $R$, Rousseau JA, et al. PET imaging of apoptosis with 64Cu-labeled streptavidin following pretargeting of phosphatidylserine with biotinylated annexin-V. Eur J Nucl Med Mol Imaging 2007;34:247-58.

41. Sosnovik DE, Schellenberger EA, Nahrendorf $M$, et al. Magnetic resonance imaging of cardiomyocyte apoptosis with a novel magneto-optical nanoparticle. Magn Reson Med 2005;54:718-24.

42. Hiller $\mathrm{KH}$, Waller $\mathrm{C}$, Nahrendorf $\mathrm{M}$, Bauer WR, Jakob PM. Assessment of cardiovascular apoptosis in the isolated rat heart by magnetic resonance molecular imaging. Mol Imaging 2006;5:115-21.

43. Schellenberger EA, Sosnovik $D$, Weissleder $R$, Josephson L. Magneto/optical annexin V, a multimodal protein. Bioconjug Chem 2004;15: 1062-7.

44. Wang $L$, Wang $F$, Fang $W$, et al. The feasibility of imaging myocardial ischemic/ reperfusion injury using $(99 \mathrm{~m}) \mathrm{Tc}$-labeled duramycin in a porcine model. Nucl Med Biol 2015; 42:198-204. 
45. Chaudhry F, Kawai $H$, Nakahara $T$, et al. Molecular imaging of apoptosis in atherosclerosis: changing the focus from phosphatidylserine to phosphatidylethanolamine. Abstract presented at: The Society of Nuclear Medicine and Molecular Imaging Mid-Winter and the American College of Nuclear Medicine Annual Meeting; January 28-3 2016; Orlando, Florida.

46. Shekhar AC, Kawai $H$, Chaudhry F, et al. Molecular imaging of apoptosis in ischemic myocardium and its modulation: targeting phosphatidylethanolamine vs. phosphatidylserine. J Nucl Cardiol 2016. 16-A-471.

47. Nakahara $T$, Petrov A, Tanimoto $T$, Haider $N$ Narula N, Chaudhry F. ${ }^{99 \mathrm{~m}} \mathrm{Tc}$-duramycin imaging detects cancer therapy related cardiac dysfunction before onset of ventricular dysfunction (abstr). J Nucl Med 2017;58 Suppl 1:586.

48. Davletov BA, Sudhof TC. A single C2 domain from synaptotagmin I is sufficient for high affinity Ca2+/phospholipid binding. J Biol Chem 1993 268:26386-90.

49. Zhao M, Zhu X, Ji S, et al. 99mTc-labeled C2A domain of synaptotagmin I as a target-specific molecular probe for noninvasive imaging of acute myocardial infarction. J Nucl Med 2006;47: 1367-74.

50. Zhao M, Beauregard DA, Loizou L, Davletov B Brindle KM. Non-invasive detection of apoptosis using magnetic resonance imaging and a targeted contrast agent. Nat Med 2001;7:1241-4

51. Wang $K$, Purushotham $S$, Lee JY, et al. In vivo imaging of tumor apoptosis using histone $\mathrm{H1}$ targeting peptide. J Control Release 2010;148: 283-91.

52. Korngold EC, Jaffer FA, Weissleder $R$, Sosnovik DE. Noninvasive imaging of apoptosis in cardiovascular disease. Heart Fail Rev 2008;13: 163-73.

53. Strijkers GJ, van Tilborg GA, Geelen $T$, Reutelingsperger CP, Nicolay K. Current applications of nanotechnology for magnetic resonance imaging of apoptosis. Methods Mol Biol 2010;624 325-42.

54. Reddy $L H$, Arias $J L$, Nicolas $J$, Couvreur $P$. Magnetic nanoparticles: design and characterization, toxicity and biocompatibility, pharmaceutical and biomedical applications. Chem Rev 2012;112: 5818-78.

55. Sosnovik DE, Nahrendorf $M$, Panizzi $P$, et al. Molecular MRI detects low levels of cardiomyocyte apoptosis in a transgenic model of chronic heart failure. Circ Cardiovasc Imaging 2009;2:468-75.

56. Bulluck $H$, White $S K$, Rosmini $S$, et al. T mapping and T2 mapping at 3T for quantifying the area-at-risk in reperfused STEMI patients. J Cardiovasc Magn Reson 2015;17:73.

57. Dall'Armellina E, Piechnik $S K$, Ferreira VM et al. Cardiovascular magnetic resonance by non contrast T1-mapping allows assessment of severity of injury in acute myocardial infarction. J Cardiovasc Magn Reson 2012;14:15.

58. Messroghli DR, Walters $K$, Plein $S$, et al. Myocardial T1 mapping: application to patients with acute and chronic myocardial infarction. Magn Reson Med 2007:58:34-40.

59. McNally LR, Mezera M, Morgan $D E$, et al. Current and emerging clinical applications of multispectral optoacoustic tomography (MSOT) in oncology. Clin Cancer Res 2016;22:3432-9.

60. Taruttis A, Wildgruber $M$, Kosanke $K$, et al. Multispectral optoacoustic tomography of myocardial infarction. Photoacoustics 2013;1:3-8.

61. Cao Y, Hui J, Kole A, et al. High-sensitivity intravascular photoacoustic imaging of lipid-laden plaque with a collinear catheter design. Sci Rep 2016;6:25236.

62. Bourantas CV, Jaffer FA, Gijsen FJ, et al. Hybrid intravascular imaging: recent advances, technical considerations, and current applications in the study of plaque pathophysiology. Eur Heart J 2017;38:400-12.

63. Madar I, Huang $Y$, Ravert $H_{\text {, et al. Detection }}$ and quantification of the evolution dynamics of apoptosis using the PET voltage sensor 18F-fluorobenzyl triphenyl phosphonium. J Nucl Med 2009;50:774-80.

64. Higuchi $T$, Fukushima $K$, Rischpler $C$, et al. Stable delineation of the ischemic area by the PET perfusion tracer F-18-fluorobenzyl tripheny phosphonium after transient coronary occlusion. J Nucl Med 2011;52:965-9.

65. Chiu ML, Kronauge JF, Piwnica-Worms D. Effect of mitochondrial and plasma membrane potentials on accumulation of hexakis (2-methoxyisobutylisonitrile) technetium (I) in cultured mouse fibroblasts. J Nucl Med 1990;31: 1646-53.

66. Perry SW, Norman JP, Barbieri J, Brown EB Gelbard HA. Mitochondrial membrane potentia probes and the proton gradient: a practical usage guide. BioTechniques 2011;50:98-115.

67. Heinrich TK, Gottumukkala V, Snay E, et al. Synthesis of fluorine-18 labeled rhodamine B: potential PET myocardial perfusion imaging agent Appl Radiat Isot 2010;68:96-100.

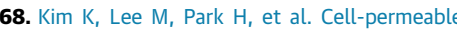
and biocompatible polymeric nanoparticles for apoptosis imaging. J Am Chem Soc 2006;128: 3490-1.

69. Zhou D, Chu W, Rothfuss J, et al. Synthesis, radiolabeling, and in vivo evaluation of an $18 \mathrm{~F}$ labeled isatin analog for imaging caspase- 3 activation in apoptosis. Bioorg Med Chem Lett 2006, 16:5041-6.

70. Bhojani MS, Hamstra DA, Chang DC, et al. Imaging of proteolytic activity using a conditional cell surface receptor. Mol Imaging 2006;5:129-37.

71. Edgington $L E$, Berger $A B$, Blum $G$, et al. Noninvasive optical imaging of apoptosis by caspase-targeted activity-based probes. Nat Med 2009:15:967-73.

72. Rosado JA, Lopez JJ, Gomez-Arteta E, et al. Early caspase-3 activation independent of apoptosis is required for cellular function. J Cell Physiol 2006;209:142-52.

73. Spires-Jones $T L$, de Calignon $A$, Matsui $T$, et al. In vivo imaging reveals dissociation between caspase activation and acute neuronal death in tangle-bearing neurons. J Neurosci 2008;28: $862-7$.

74. Muzzammil $T$, Moore MJ, Hedley $D$, et al, Comparison of (99m) Tc-sestamibi and doxorubicin to monitor inhibition of P-glycoprotein function. Br J Cancer 2001;84:367-73.

75. Challapalli A, Kenny LM, Hallett WA, et al. F-ICMT-11, a caspase-3-specific PET tracer for apoptosis: biodistribution and radiation dosimetry. J Nucl Med 2013;54:1551-6.

76. Thukkani AK, Shoghi KI, Zhou D, et al. PET imaging of in vivo caspase-3/7 activity following myocardial ischemia-reperfusion injury with the radiolabeled isatin sulfonamide analogue [(18)F] WC-4-116. Am J Nucl Med Mol Imaging 2016;6: $110-9$

77. Takemura G, Kanoh M, Minatoguchi S Fujiwara H. Cardiomyocyte apoptosis in the failing heart-a critical review from definition and classification of cell death. Int J Cardiol 2013;167: 2373-86.

78. Kockx MM, Knaapen MW. Pathological changes in the coronary arteries in the acute coronary syndromes. Heart 2006;92:1557-8.

79. Bjorkerud S, Bjorkerud B. Apoptosis is abundant in human atherosclerotic lesions, especially in inflammatory cells (macrophages and T cells) and may contribute to the accumulation of gruel and plaque instability. Am J Pathol 1996;149:367-80.

80. Kolodgie FD, Narula J, Burke AP, et al. Localization of apoptotic macrophages at the site of plaque rupture in sudden coronary death. Am Pathol 2000;157:1259-62.

81. Virmani $R$, Burke AP, Farb A, Kolodgie FD. Pathology of the vulnerable plaque. J Am Coll Cardiol 2006;47 Suppl 8:C13-8.

82. Mallat $Z$, Hugel $B$, Ohan J, Leseche $G$ Freyssinet JM, Tedgui A. Shed membrane microparticles with procoagulant potential in human atherosclerotic plaques: a role for apoptosis in plaque thrombogenicity. Circulation 1999;99:348-53.

83. Isobe S, Tsimikas S, Zhou J, et al. Noninvasive imaging of atherosclerotic lesions in apolipoprotein E-deficient and low-density lipoprotein receptor-deficient mice with annexin A5. J Nucl Med 2006;47:1497-505.

84. Kolodgie FD, Petrov $A$, Virmani $R$, et al. Targeting of apoptotic macrophages and experimental atheroma with radiolabeled annexin V: a technique with potential for noninvasive imaging of vulnerable plaque. Circulation 2003;108: 3134-9.

85. Johnson LL, Schofield $L$, Donahay $T$, Narula $N$ Narula J. 99mTc-annexin $\mathrm{V}$ imaging for in vivo detection of atherosclerotic lesions in porcine coronary arteries. J Nucl Med 2005;46:1186-93.

86. Hartung $D$, Sarai $M$, Petrov $A$, Kolodgie $F$, Narula N, Verjans J, Virmani R, Reutelingsperger C, Hofstra L, Narula J. Resolution of apoptosis in atherosclerotic plaque by dietary modification and statin therapy. J Nucl Med 2005;46:2051-6.

87. Olivetti G, Quaini F, Sala $R$, et al. Acute myocardial infarction in humans is associated with activation of programmed myocyte cell death in the surviving portion of the heart. J Mol Cell Cardiol 1996:28:2005-16. 
88. Gottlieb RA, Burleson $K O$, Kloner $R A$, Babior BM, Engler RL. Reperfusion injury induces apoptosis in rabbit cardiomyocytes. J Clin Invest $1994 ; 94: 1621-8$

89. Kajstura J, Cheng W, Reiss K, et al. Apoptotic and necrotic myocyte cell deaths are independent contributing variables of infarct size in rats. Lab Invest 1996;74:86-107.

90. Sam F, Sawyer DB, Chang DL, et al. Progressive left ventricular remodeling and apoptosis late after myocardial infarction in mouse heart. Am J Physiol Heart Circ Physiol 2000;279:H422-8.

91. Foo RS, Mani K, Kitsis RN. Death begets failure in the heart. J Clin Invest 2005;115:565-71.

92. Garg S, Hofstra L, Reutelingsperger C, Narula J. Apoptosis as a therapeutic target in acutely ischemic myocardium. Curr Opin Cardiol 2003;18:372-7.

93. Fonge $\mathrm{H}$, de Saint Hubert $M$, Vunckx $K$, et al. Preliminary in vivo evaluation of a novel $99 \mathrm{mTc}$ labeled HYNIC-cys-annexin A5 as an apoptosis imaging agent. Bioorg Med Chem Lett 2008;18: 3794-8.

94. Dumont $E A$, Reutelingsperger $C P$, Smits $J F$, et al. Real-time imaging of apoptotic cellmembrane changes at the single-cell level in the beating murine heart. Nat Med 2001;7:1352-5.

95. Thimister PW, Hofstra L, Liem IH, et al. In vivo detection of cell death in the area at risk in acute myocardial infarction. J Nucl Med 2003;44:391-6.

96. Narula J, Haider N, Virmani R, et al. Apoptosis in myocytes in end-stage heart failure. $N$ Engl J Med 1996;335:1182-9.
97. Olivetti G, Abbi R, Quaini F, et al. Apoptosis in the failing human heart. N Engl J Med 1997;336: 1131-41.

98. Saraste A, Pulkki K, Kallajoki M, et al. Cardiomyocyte apoptosis and progression of heart failure to transplantation. Eur J Clin Invest 1999; 29:380-6.

99. Chandrashekhar $Y$, Sen S, Anway R, Shuros A, Anand I. Long-term caspase inhibition ameliorates apoptosis, reduces myocardial troponin-I cleavage, protects left ventricular function, and attenuates remodeling in rats with myocardial infarction. J Am Coll Cardiol 2004;43:295-301.

100. Wencker $D$, Chandra $M$, Nguyen $K$, et al. A mechanistic role for cardiac myocyte apoptosis in heart failure. J Clin Invest 2003:111:1497-504.

101. Hayakawa $Y$, Chandra M, Miao $W$, et al. Inhibition of cardiac myocyte apoptosis improves cardiac function and abolishes mortality in the peripartum cardiomyopathy of Galpha(q) transgenic mice. Circulation 2003; 108:3036-41.

102. Kytö V, Saraste A, Saukko P, et al. Apoptotic cardiomyocyte death in fatal myocarditis. Am J Cardiol 2004;94:746-50.

103. Colston JT, Chandrasekar B, Freeman GL. Expression of apoptosis-related proteins in experimental coxsackievirus myocarditis. Cardiovasc Res 1998;38:158-68.

104. Ventéo $L$, Bourlet $T$, Renois $F$, et al. Enterovirusrelated activation of the cardiomyocyte mitochondrial apoptotic pathway in patients with acute myocarditis. Eur Heart J 2010;31:728-36.

105. Peker C, Sarda-Mantel L, Loiseau $P$, et al. Imaging apoptosis with $(99 \mathrm{~m}) \mathrm{Tc}$-annexin- $\mathrm{V}$ in experimental subacute myocarditis. J Nucl Med 2004;45:1081-6.

106. Petillot $P$, Lahorte $C$, Bonanno $E$, et al. Annexin $V$ detection of lipopolysaccharideinduced cardiac apoptosis. Shock 2007:27:69-74.

107. Bennink RJ, van den Hoff MJ, van Hemert FJ, et al. Annexin $\mathrm{V}$ imaging of acute doxorubicin cardiotoxicity (apoptosis) in rats. J Nucl Med 2004;45:842-8.

108. Blankenberg F, Narula J, Strauss HW. In vivo detection of apoptotic cell death: a necessary measurement for evaluating therapy for myocarditis, ischemia, and heart failure. J Nucl Cardiol 1999;6:531-9.

109. Tokita $N$, Hasegawa $S$, Maruyama $K$, et al. 99mTc-Hynic-annexin $V$ imaging to evaluate inflammation and apoptosis in rats with autoimmune myocarditis. Eur J Nucl Med Mol Imaging 2003;30:232-8.

110. Kown MH, Strauss HW, Blankenberg FG, et al. In vivo imaging of acute cardiac rejection in human patients using (99 m) technetium labeled annexin V. Am J Transplant 2001;1: 270-7.

111. Min Y, Li J, Liu F, Yeow EK, Xing B. Nearinfrared light-mediated photoactivation of a platinum antitumor prodrug and simultaneous cellular apoptosis imaging by up-conversion-luminescent nanoparticles. Angew Chem Int Ed 2014;53: 1012-6.

KEY WORDS coronary artery stenosis, myocardial ischemia, revascularization, stable ischemic heart disease, vulnerable plaque 